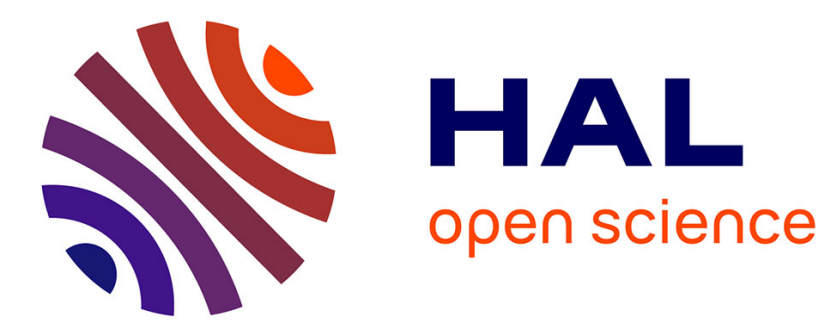

\title{
Recent advances on carbazole-based photoinitiators of polymerization
}

Frederic Dumur

\section{To cite this version:}

Frederic Dumur. Recent advances on carbazole-based photoinitiators of polymerization. European Polymer Journal, 2020, 125, pp.109503. 10.1016/j.eurpolymj.2020.109503 . hal-02866914

\section{HAL Id: hal-02866914 https://hal.science/hal-02866914}

Submitted on 2 Jul 2020

HAL is a multi-disciplinary open access archive for the deposit and dissemination of scientific research documents, whether they are published or not. The documents may come from teaching and research institutions in France or abroad, or from public or private research centers.
L'archive ouverte pluridisciplinaire HAL, est destinée au dépôt et à la diffusion de documents scientifiques de niveau recherche, publiés ou non, émanant des établissements d'enseignement et de recherche français ou étrangers, des laboratoires publics ou privés. 


\title{
Recent advances on carbazole-based photoinitiators of polymerization
}

\author{
Frédéric Dumur
}

Aix Marseille Univ, CNRS, ICR, UMR 7273, F-13397 Marseille, France

\section{A R T I C L E IN F O}

\section{Keywords}

Photoinitiator

Carbazole

Photopolymerization

LED

Iodonium

Ferrocenium

Carbazolium

\begin{abstract}
A B S T R A C T
Photoinitiators of polymerization that can be activated under visible light and low intensity are actively researched as these compounds constitute the next generation of photoinitiators that will replace the controverted UV-photoinitiators. Over the years, a family of compounds has been identified as being highly promising in light of its remarkable photoinitiating ability, photochemical stability, low cost and easiness to functionalize, namely carbazoles. In this review, an overview of the different carbazole-based photoinitiators reported to date is presented. Interestingly, carbazoles have mostly been used as electron donors in push-pull structures, as photosensitizers for iodonium salts, as ligands for ferrocenium salts or as chromophores for phenacyl onium salts. These different applications clearly demonstrate the versatility of this structure used as the elemental building block for the design of UV, near-UV or visible light photoinitiators.
\end{abstract}

\section{Introduction}

During the past decades, photopolymerization carried out under low light intensity and visible light has been the focus of numerous research efforts due to the wide range of applications in which this polymerization technique is involved, ranging from coatings, adhesives, high-tech applications [1], 3D printing [2] and more recently the polymerization of thick samples comprising a high content of fillers [3,4]. From a technical point of point, photopolymerization exhibits several advantages compared to the traditional thermal polymerization done in solution. Notably, a temporal and a spatial control of the polymerization process can be obtained [5-7]. The polymerization process can also be extremely fast, the polymerization being ended after a few seconds (See Fig. 1) [8,9]. Parallel to this, photopolymerization can be carried out in solvent-free conditions, avoiding the release of volatile organic compounds (VOC) [10]. At present, most of the polymerization processes done in industries are based on UV-photoinitiators giving rise to safety concerns for the manipulators. Notably, UV-light can be responsible from eye damages under accidental exposure $[11,12]$. This unwanted exposure can nonetheless occur in industry but also during dental treatments in dental clinics so that alternatives to UV light photoinitiators are actively researched [13].

Besides, UV photoinitiators remains appealing candidates for photopolymerization due to their lack of color, these compounds being white powders. As a result of this, colorless polymers can be obtained, their incorporation into photocurable resins unaffecting the color of the resins and thus that of the final polymers. Conversely, visible light photoinitiators are colored compounds and the final polymers are most of the time highly colored even if low amounts of photoinitiators are classically used. In this context, a great deal of efforts has been devoted to develop photoinitiators capable to bleach i.e. to become colorless after a prolonged light irradiation or during the polymerization time. At present, examples of photoinitiators capable to bleach remain scarce [14]. In this field, metal complexes are excellent candidates and acylstannanes 1, 2 [15,16]. or acylgermanes (ivocerin 3, tetrakis(2-methylbenzoyl)germane 4) $[17,18]$ can be cited as type I photoinitiators exhibiting the most remarkable photobleaching properties (See Fig. 2). But, examples of type II photoinitiators also exist as exemplified with a substituted (dithiophene)diketopyrrolopyrrole 5 [19], a zinc complex bearing oxadiazoles as pendant groups 6 [20], a cyclohexan-1-one derivative 7 [21] or a carboxylated camphorquinone 8 [22].

Parallel to safety concerns, light penetration inside the photocurable resin is another parameter governing the polymerization efficiency [23]. As evidenced in the Fig. 3 for a polystyrene latex with an average diameter of $112 \mathrm{~nm}$, the light penetration ranges from $600 \mu \mathrm{m}$ at $320 \mathrm{~nm}$ (i.e. in the UV region) to $5 \mathrm{~cm}$ at $800 \mathrm{~nm}$ (i.e. in the near-infrared region), completely modifying the scope of applications of photopolymerization. Indeed, if historically, photopolymerization which was based on UV photoinitiators was limited to coatings due to the poor light penetration inside the polymerizable resins, the access to thick samples containing fillers is now possible, revolutionizing the possibilities of photopolymerization (See Fig. 3).

At present, numerous families of organic dyes have been developed as type II photoinitiators activable under low light intensity and visible light. Among them, chalcones 9 [24], chromones 10 [25-27], perylenes 11 [28-30], diketopyrrolopyrroles 12 [31-33], acridine-1,8-diones 13 [34-36], naphthalimides 14 [37-47], iodonium salts

E-mail address: Frederic.dumur@univ-amu.fr (F. Dumur) 
A

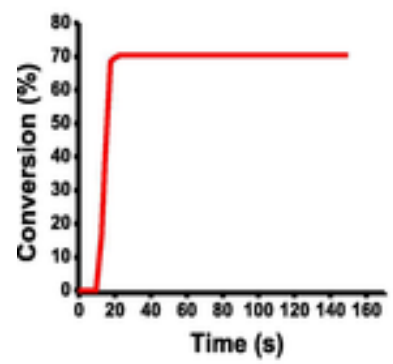

High polymerization speed
B

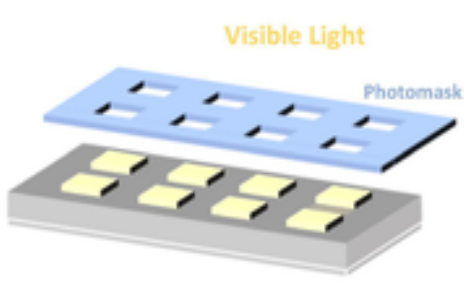

Spatial control
C

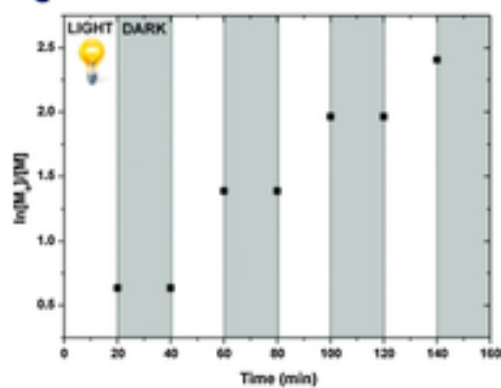

Temporal control

Fig. 1. The different advantages of photopolymerization.

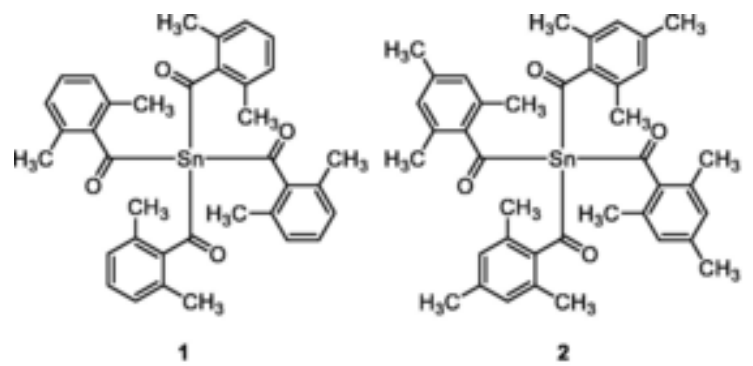<smiles>CCC(C(=O)c1ccc(OC)cc1)C(=O)c1ccc(OC)cc1</smiles><smiles>Cc1ccccc1C(=O)OC(C(=O)c1ccccc1C)(C(=O)c1ccccc1C)C(=O)c1ccccc1C</smiles>

Ivocerin 3

4
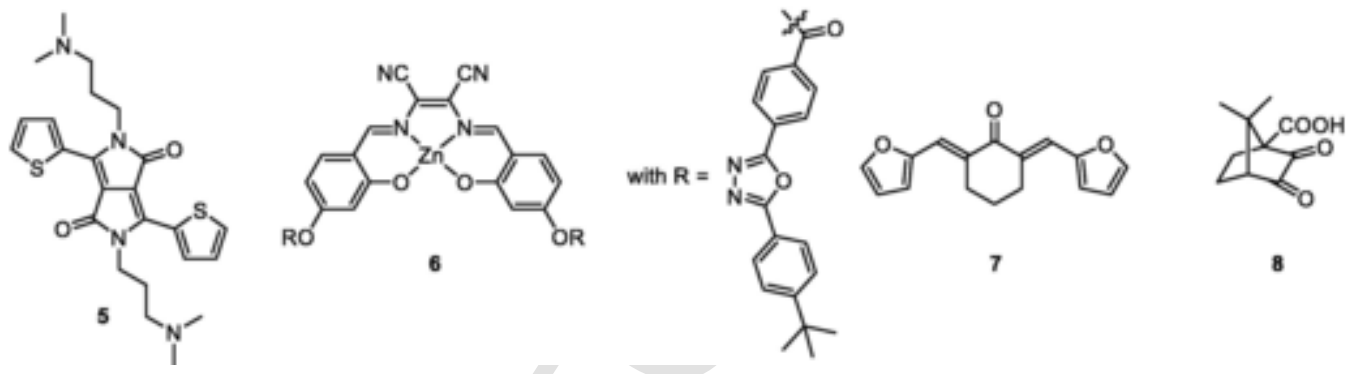

Fig. 2. Examples of type I and type II photoinitiators reported in the literature as being capable to bleach under light irradiation.

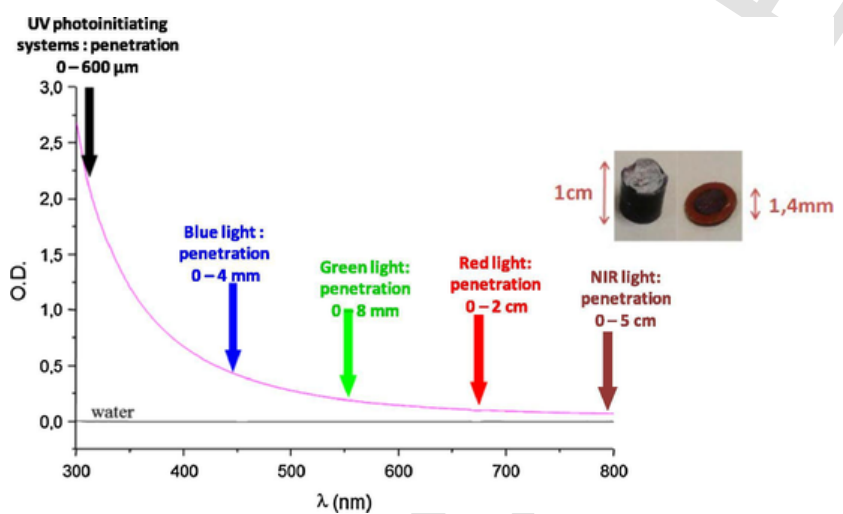

Fig. 3. Light penetration inside a polystyrene latex with an average diameter of $112 \mathrm{~nm}$. Inset: examples of polymerized resins containing fillers. Reproduced with permission from Bonardi et al. [23]. Copyright 2018 American Chemical Society.

$15[48,49]$, squaraines 16, bodipys 17 and porphyrins 18 [50,51], pyrenes 19 [52-55], benzophenones 20 [56-59], push-pull dyes 21 [60-69], coumarines 22 [70], 2,3-diphenylquinoxaline derivatives 23 [71], pyridinium derivatives 24 [72], or dihydroxy-anthraquinones 25 [73] can be cited the most relevant examples (See Fig. 4).

Since a decade and due to the fact that the traditional families of UV photoinitiators are not adapted for the design of visible light photoinitiators, even after extensive works of chemical engineering, new families of compounds and especially dyes that have never been ex- plored in the context of photopolymerization are now classically tested by polymerists. Considering that visible light photoinitiators should strongly absorb in the visible range, be chemically stable, and that these compounds should also be capable to be reduced or oxidized in an acceptable electrochemical window, all organic dyes examined in Organic Electronics (organic solar cells, organic light-emitting diodes, organic field-effect transistors) are potential candidates for photoinitiation [74]. In this field, carbazole is a representative example. This symmetric structure which is extremely cheap has been extensively studied in Organic Electronics due to its remarkable electron-donating ability, its low oxidation potential and its facile chemical modification so that a wide range of hole-transport materials $[75,76]$, molecular glasses [77-80], or light-emitting materials [81-85] have been designed with carbazole. Considering that push-pull dyes can be easily synthesized with this electron donor, carbazole was also an excellent candidate for the design of light-harvesting materials for solar cells, and numerous dyes exhibiting high molar extinction coefficients and broad absorption spectra were obtained with this planar electron donor [86,87]. Carbazole is a polyaromatic structure comprising two benzene rings fused on both sides of a nitrogen-containing five-membered ring (See Fig. 5) [88]. The central position of the nitrogen atom allows to write resonance forms with an electronic delocalization extending over the two aromatic rings. By the presence of the amine, the nitrogen atom can be functionalized with alkyl chains to improve the solubility of photoinitiators. By quaternization of the amine, carbazolium salts can also be prepared $[89,90]$. The 3 - and 6-positions of carbazole can also be eas- 
<smiles>O=C(/C=C/c1ccccc1)c1ccccc1O</smiles>

chalcone 9<smiles>[R]c1ccc(C2C3=C(CCCC3=O)N([Y20]([H])(C)[O-])C3=C2C(=O)CCC3)cc1</smiles>

acridine-1,8-dione 13<smiles>[R]c1ccc(-c2oc3ccccc3c(=O)c2[R])cc1</smiles>

chromone 10<smiles></smiles>

naphthalimide 14

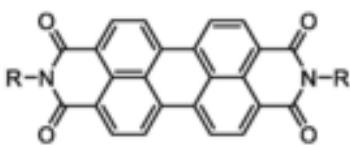

perylene 11<smiles>[R]c1c2c(c(CC)n1CC)C(=O)N([R])C2=O</smiles>

diketopyrrolopyrrole 12
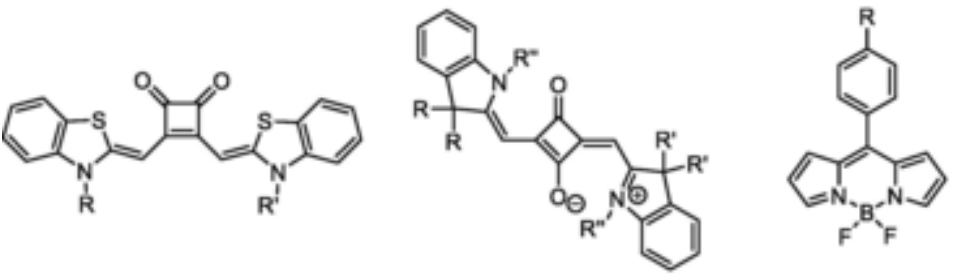

bodipy 17<smiles>CN(C)c1ccc(C=C2C(=O)c3ccccc3C2=O)cc1</smiles>

push-pull dyes $\mathbf{2 1}$

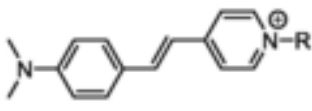

Pyridinium derivatives 24<smiles>O=C(c1ccccc1)c1ccc(N2C(=O)c3cccc4cccc(c34)C2=O)cc1</smiles>

iodonium salts 15 squaraines 16

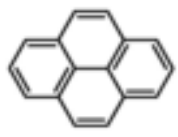

pyrene 19

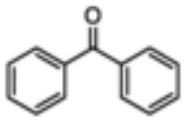

benzophenone 20

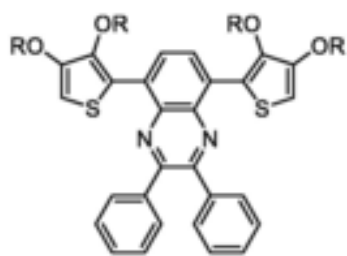

2,3-diphenylquinoxaline derivatives 23

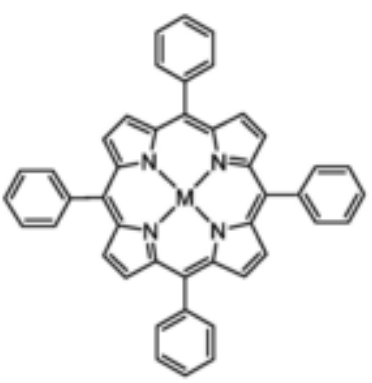

porphyrin 18<smiles>CCN(CC)c1ccc2cc(-c3cccs3)c(=O)oc2c1</smiles>

coumarine 22<smiles>O=C1c2ccccc2C(=O)c2c(O)cccc21</smiles>

dihydroxyanthraquinone 25

Fig. 4. Different families of compounds (9-25) examined as visible light photoinitiators of polymerization activable under low light intensity.

ily functionalized with various groups such as aldehyde, halogens and nitro groups so that an extension of conjugation or the introduction of various groups can be carried out. Parallel to the modification of the carbazole core, carbazole is also an electron-rich polyaromatic group that can be used for the design of ferrocenium salts, these iron complexes being prepared by ligand exchange on ferrocene [91].

Concerning photopolymerization, $N$-vinylcarbazole (NVK) is classically used as an additive improving the final monomer conversion due to the possibility for the photogenerated radicals to add onto the vinylic group of NVK [92,93]. In fact, NVK is capable to convert hardly oxidizable radicals formed by the photoinitiating systems to easily oxidizable ones so that it often constitutes the key element enabling to get high final monomer conversions. To get this impressive result, a careful examination of the polymerization mechanism should be carried out. Typically, to get a significant enhancement of the final monomer conversion with NVK, this latter should be added to two-component systems comprising a photoinitiator (PI) and an iodonium salt $\left(\mathrm{Ph}_{2} \mathrm{I}^{+}\right)$(See Scheme 1) $[94,95]$. When the photosensitizer is excited to its triplet state by light irradiation, it can thus reduce $\mathrm{Ph}_{2} \mathrm{I}^{+}$to
$\mathrm{Ph}_{2}{ }^{*}$ which subsequently decompose to $\mathrm{Ph}^{*}$ (and Ph-I), constituting an initiating species for the free radical polymerization (FRP) of acrylates. However, by reacting with the phenyl radical $\mathrm{Ph}^{*}$, NVK can also give a highly reactive speries $\mathrm{Ph}-\mathrm{NVK}^{*}$, initiating more efficiently the FRP of acrylates than $\mathrm{Ph}^{\circ}$. Parallel to photoinitiation, $\mathrm{Ph}-\mathrm{NVK}^{*}$ can also react with the oxidized form of the photoinitiator $\mathrm{PI}^{+}$, generating the $\mathrm{Ph}-\mathrm{NVK}^{+}$species capable to initiate the free radical promoted cationic polymerization (FRPCP) of epoxides. $\mathrm{Ph}-\mathrm{NVK}^{\bullet}$ can also oxidized by $\mathrm{Ph}_{2} \mathrm{I}^{+}$which is used in excess so that $\mathrm{Ph}-\mathrm{NVK}^{+}$species can be obtained by this second route. Therefore, due to the possibility of a dual cure process, the three-component system $\mathrm{PI} / \mathrm{Ph}_{2} \mathrm{I}^{+} / \mathrm{NVK}$ has been extensively studied in the literature as it opens the way towards the generation of interpenetrated networks (IPNs) where the simultaneous polymerization of acrylates and epoxides provides crosslinked polymers of unique photophysical and mechanical properties. Due to the reduction of $\mathrm{PI}^{+}$to $\mathrm{PI}$ and thus its regeneration, the photoinitiator can thus be introduced into catalytic amount in the photoinitiating system. The catalytic cycle reported in the Scheme 1 is therefore a typical photoredox 

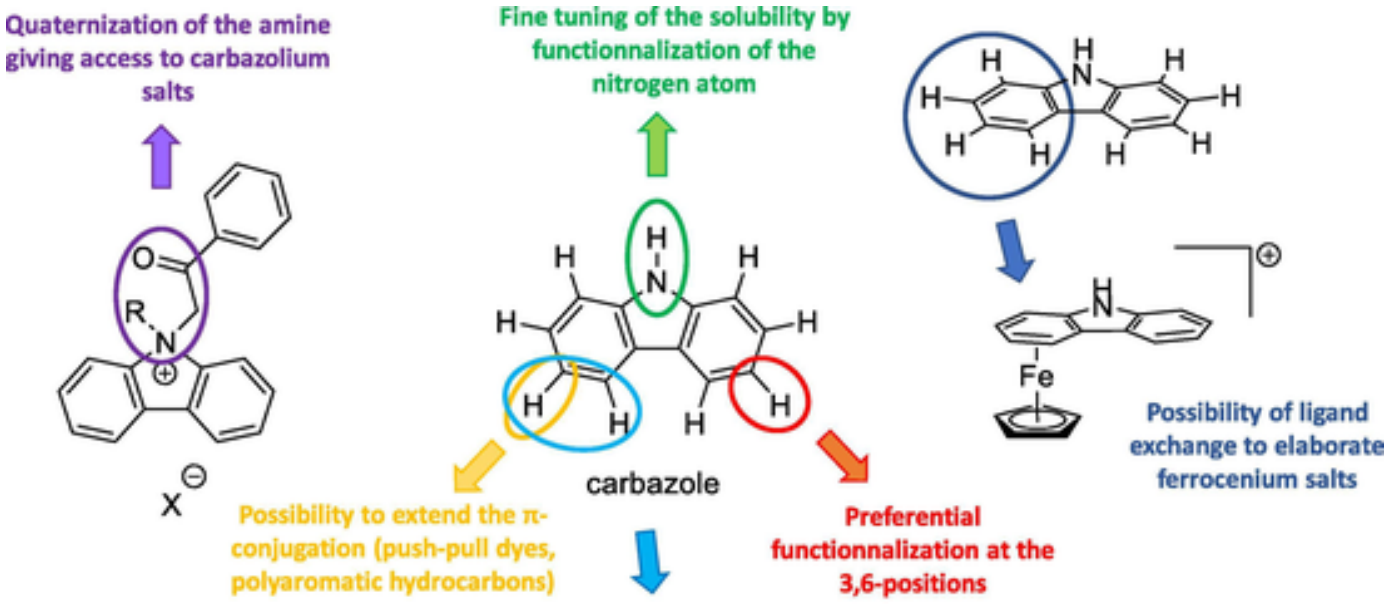

Formation of helicenes by orthocondensation of aromatic rings

Fig. 5. The different possible chemical modifications on the carbazole core.

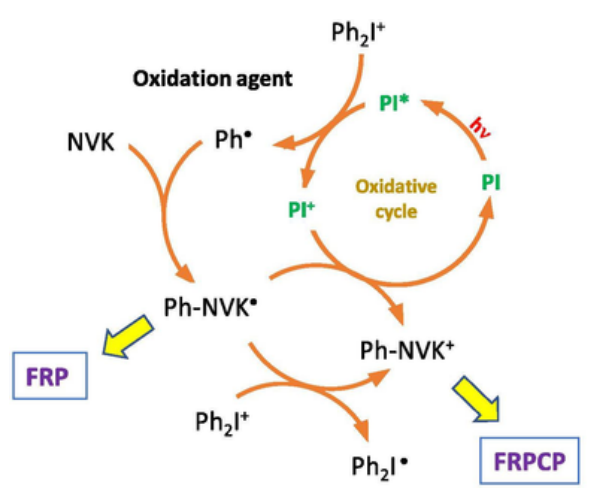

Scheme 1. Photoredox catalytic cycle involving a three-component system.

catalytic cycle. Parallel to the development of photoinitiators based on carbazole, a new application has recently been reported for a carbazole derivative, namely, its use as a fluorescent probe to monitor the cationic photopolymerization process by fluorescence measurements. It therefore evidences the versatility of carbazoles in polymerization [96].

In this review, an overview of the different photoinitiators comprising the carbazole moiety is presented. Over the years, different strategies have been developed to take advantage of the carbazole scaffold and push-pull dyes, nitrogen-containing polyaromatic hydrocarbons, helicenes, ferrocenium or carbazolium, and more recently photoinitiators exhibiting a thermally activated delayed fluorescence (TADF) property have been synthesized as tested in photopolymerization. To evidence the interest of these different families of photoinitiators, performances of these photoinitiators in FRP and FRPCP is presented.

\section{Carbazoles as photoinitiators of polymerization}

\subsection{Push-pull dyes}

As mentioned in the introduction section, carbazole has been extensively used for the design of push-pull dyes due to its remarkable electron-donating ability. Push-pull dyes are composed of an electron-donating and an electron accepting moiety connected by mean of a conjugated spacer (See Fig. 6).

Among all possible chemical reactions to create a double bond, the Knoevenagel reaction is a reaction of choice, opposing an aldehyde to an activated methylene group. The first report mentioning this coupling mode was published in 1896 by Knoevenagel, consisting in the conden- sation of benzaldehyde with ethyl acetoacetate in the presence of piperidine [97]. The first product synthesized by mean of this reaction could be obtained in $95 \%$ yield. From an industrial point of view, this reaction is of crucial interest as this reaction is easy to perform, can be done in Green solvents such as ethanol and even in solvent-free conditions, by mechanosynthesis [98]. Irrespective of the synthetic approach, the side product of this reaction is safe and limited to a water molecule. Considering that both the electron donor and the electron acceptor can be commercially available, numerous push-pull dyes have been designed and examined as photoinitiators of polymerization.

As far as carbazoles are concerned, the first report mentioning the design of carbazole-based push-pull dyes for photopolymerization applications was published in 2013 by Lalevée and coworkers [99]. Cbz_1 and $\mathbf{C b z}_{-} \mathbf{2}$ were prepared in one step, starting from 9-octyl-9H-carbazole-3-carbaldehyde 26, barbituric acid 27 and thiobarbituric acid 28 respectively. The two dyes $\mathbf{C b z} \mathbf{1}$ and $\mathbf{C b z} \mathbf{2}$ could be obtained by refluxing the two precursors in ethanol, in 78 and $85 \%$ yields respectively (See Scheme 2). Interestingly, $\mathbf{C b z} \mathbf{1}$ and $\mathbf{C b z} \mathbf{2}$ exhibited a broad intramolecular charge transfer (ITC) band ranging between 350 and $500 \mathrm{~nm}$ for Cbz_1, 375 and $550 \mathrm{~nm}$ for $\mathbf{C b z}_{-} 2$ respectively so that photopolymerization experiments could be carried out upon irradiation with laser diodes emitting at 457 and $473 \mathrm{~nm}$ or a LED bulb emitting at $462 \mathrm{~nm}$ (See Fig. 7).

High molar extinction coefficients were determined at the absorption maxima of the two complexes, $45000 \mathrm{M}^{-1} \mathrm{~cm}^{-1}$ at $431 \mathrm{~nm}$ for Cbz_1 and $37000 \mathrm{M}^{-1} \mathrm{~cm}^{-1}$ at $462 \mathrm{~nm}$ for $\mathrm{Cbz}_{-} 2$ respectively. However, despites the similar of structures, completely different behaviors were observed upon photolysis of Cbz_1 and Cbz_2. Upon exposure to a laser diode at $473 \mathrm{~nm}$, a fast photobleaching of the 


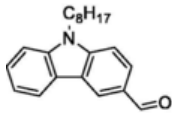

26<smiles>O=C1CC(=O)NC(=O)N1</smiles>

27

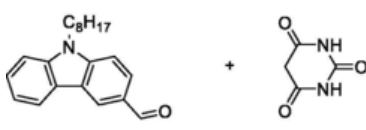

26

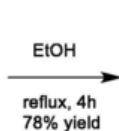

$78 \%$ yield

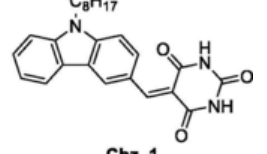

Cbz 1

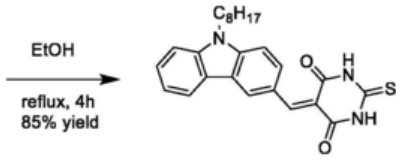

Cbz_2
Scheme 2. Synthetic route to $\mathrm{Cbz}_{-} 1$ and $\mathrm{Cbz}_{-} 2$

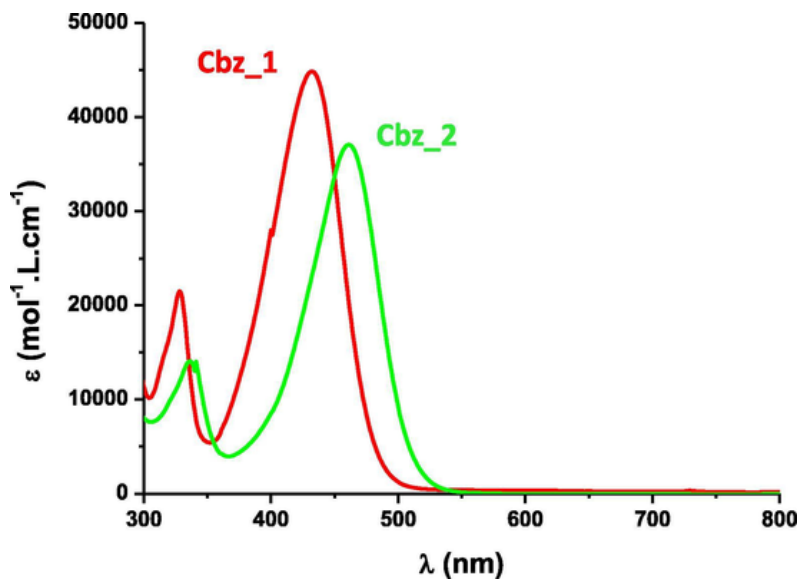

Fig. 7. UV-visible absorption spectra of Cbz_1 and Cbz_2 in acetonitrile. Reprinted with permission from Tehfe et al. [99] Copyright (C) 2013 John Wiley \& Sons, Inc.

Cbz_2/diphenyliodonium hexafluorophosphate $\left(\mathrm{Ph}_{2} \mathrm{I}^{+}\right)$mixture was observed, indicating the dyes to be oxidized by the iodonium salt and to result in its decomposition (see equations $\mathrm{r}(1)$ and $\mathrm{r}(2)$ ). In the presence of NVK, $\mathrm{Ph}^{*}$ is rapidly converted to $\mathrm{Ph}-\mathrm{NVK}^{*}$ (r3) by addition on the double bond. This radical can be easily oxidized by $\mathrm{Ph}_{2} \mathrm{I}^{+}$, providing $\mathrm{Ph}^{-\mathrm{NVK}^{+}}$(r4a) but $\mathrm{Ph}-\mathrm{NVK}^{*}$ can also reduce the oxidized form of the dye (r4b), regenerating the dye. Overall, by the formation of Ph-NVK and $\mathrm{Ph}-\mathrm{NVK}^{+}$, both the free radical polymerization (FRP) of acrylates (r6) or the free radical promoted cationic polymerization (FRPCP) of epoxides (r5) can be initiated.

dye $\rightarrow{ }^{1}$ dye $(h \nu)$

${ }^{1}$ dye $+\mathrm{Ph}_{2} \mathrm{I}^{+} \rightarrow$ dye ${ }^{\bullet+}+\mathrm{Ph}_{2} \mathbf{I}^{*}$

$$
\begin{aligned}
& \mathrm{Ph}_{2} \mathrm{I}^{*} \rightarrow \mathrm{Ph}^{*}+\mathrm{Ph}-\mathrm{I} \\
& \mathrm{Ph}^{\bullet}+\mathrm{NVK} \rightarrow \mathrm{Ph}-\mathrm{NVK}{ }^{\bullet} \\
& \mathrm{Ph}-\mathrm{NVK}^{*}+\mathrm{Ph}_{2} \mathrm{I}^{+} \rightarrow \mathrm{Ph}-\mathrm{NVK}^{+}+\mathrm{Ph}-\mathrm{I}+\mathrm{Ph}^{\bullet} \\
& \mathrm{Ph}^{-N_{V K}}+\text { dye }^{\bullet} \rightarrow \mathrm{Ph}^{+} \mathrm{NVK}^{+}+\text {dye }
\end{aligned}
$$

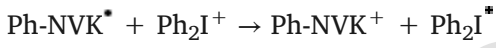

$$
\begin{aligned}
& \mathrm{Ph}^{-N_{V K}}{ }^{+}+\mathrm{M} \rightarrow \text { Ph-NVK-M }{ }^{+} \\
& \mathrm{Ph}-\mathrm{NVK}^{*}+\mathrm{M}^{\prime} \rightarrow \mathrm{Ph}-\mathrm{NVK}-\mathrm{M}^{\prime}
\end{aligned}
$$

On the opposite, a completely different behavior was observed with Cbz_1, the photolysis of the $\mathbf{C b z}_{-} \mathbf{1} / \mathrm{Ph}_{2} \mathrm{I}^{+}$mixture being extremely slow (See Fig. 8). This counter-nerformance was assigned to a back electron-transfer between $\mathrm{Cbz}_{-} \mathbf{1}^{+}$and $\mathrm{Ph}_{2} \mathbf{I}^{*}$ in $\mathrm{r}$.

While examining the polymerization profiles of (3,4-epoxycyclohexane)methyl 3,4-epoxycyclohexylcarboxylate (EPOX) upon irradiation at $473 \mathrm{~nm}$, the three-component system $\mathrm{Cbz}_{-} 1 / \mathrm{NVK}_{\mathrm{Ph}} \mathrm{I}^{+}(0.3 \% /$ $3 \% / 2 \% \mathrm{w} / \mathrm{w}$ ) proved to be ineffective to initiate a polymerization whereas a final monomer conversion of $55 \%$ could be obtained within $800 \mathrm{~s}$ for the three-component system $\mathrm{Cbz}_{-} 2 / \mathrm{NVK} / \mathrm{Ph}_{2} \mathrm{I}^{+}(0.3 \% / 3 \% / 2 \%$ $\mathrm{w} / \mathrm{w})$. A similar monomer conversion could be obtained with the LED bulb at $462 \mathrm{~nm}$ with $\mathbf{C b z}_{-} 2$, the absorption of $\mathbf{C b z}_{-} 2$ being similar at 462 and $473 \mathrm{~nm}$.

While examining the FRP of trimethylolpropane triacrylate (TMPTA) (See Fig. 9), no polymerization was observed with $\mathbf{C b z}_{-} \mathbf{1}$ whereas a final monomer conversion of $45 \%$ could be obtained within $300 \mathrm{~s}$ with the three-component system Cbz_2/NVK/Ph ${ }_{2} \mathrm{I}^{+}(0.3 \% / 3 \% / 2 \% \mathrm{w} / \mathrm{w})$.

Finally, an interesting finding was determined while examining the solvatochromism of $\mathbf{C b z}_{-} \mathbf{1}$ and $\mathbf{C b z}_{-} \mathbf{2}$ in solvents of different polarity. Surprisingly, if a linear correlation could be established with different empirical scales of solvent polarity such as the Bakhshiev's [100], the Lippert-Mataga [101], the Kawski-Chamma-Viallet's [102], the McRae's [103] or the Suppan's [104] scales with Cbz_2, no linear correlation could be established for $\mathbf{C b z}_{-} \mathbf{1}$. This unexpected behavior for $\mathbf{C b z}_{-} \mathbf{1}$ was assigned to the formation of hydrogen bonds with the solvents, altering the solvatochromic behavior of this compound (See Scheme 3). Besides, a direct correlation between solvatochromism and photoinitiating ability can be established and this point is an important finding.

As evidenced by the authors in this work but also in other studies making use of push-pull dyes as photoinitiators, only the dyes exhibiting a solvatochromism that can be rationalized with classical solva-
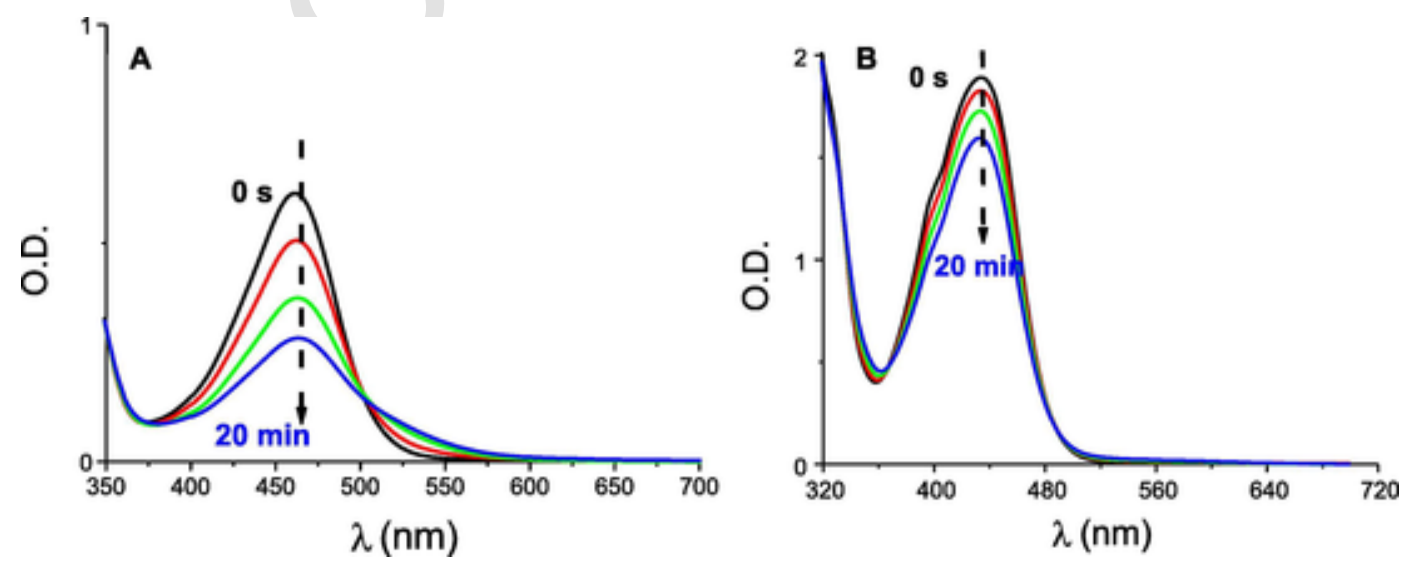

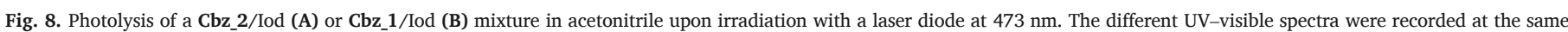
irradiation times under air. Reprinted with permission from Tehfe et al. [99] Copyright (C) 2013 John Wiley \& Sons, Inc. 

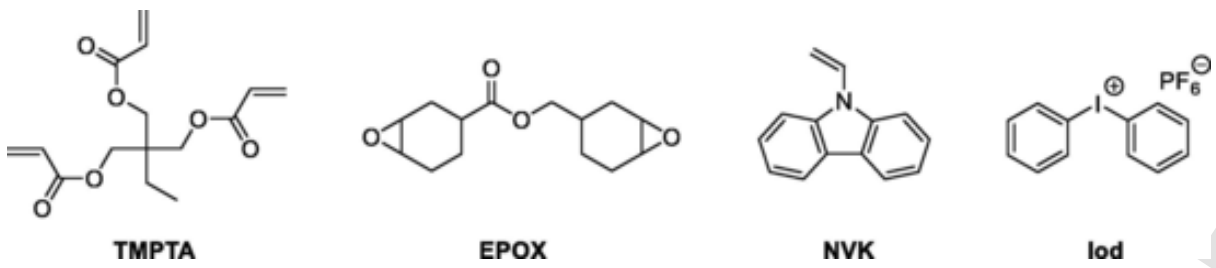

Fig. 9. Chemical structures of the different monomers and additives used with $\mathrm{Cbz}_{-} \mathbf{1}$ and $\mathbf{C b z} \mathbf{2}$.

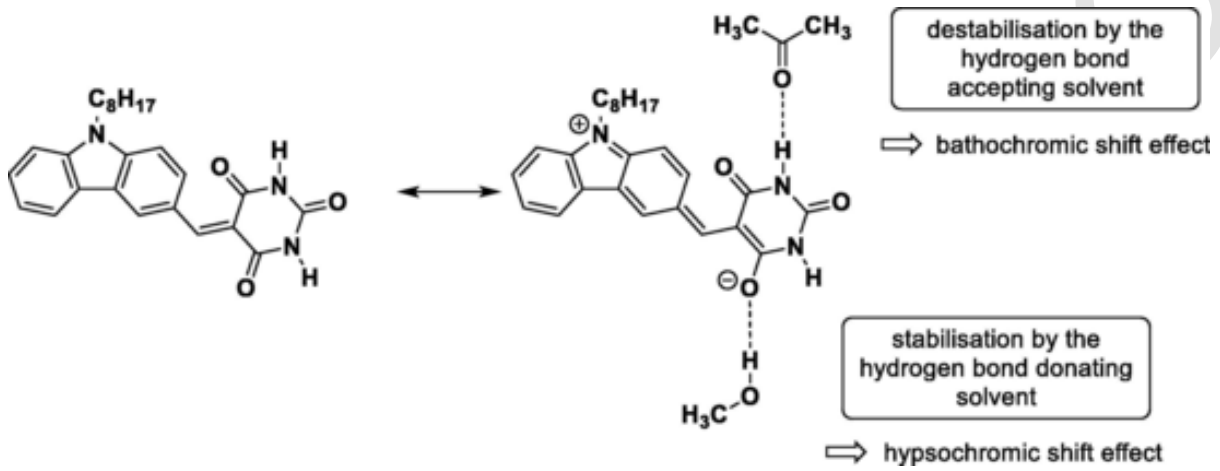

Scheme 3. The different parameters affecting the solvatochromic behavior of Cbz_1.

tochromic scales can initiate a polymerization process. Finally, authors proved that by simply examining the solvatochromism of the newly synthesized push-pull dyes, the photoinitiating abilities of theses chromophores could be efficiently anticipated.

Considering the strong structure/reactivity relationship exists for this class of dyes, another carbazole-based dye $\mathbf{C b z}_{-} \mathbf{3}$ was examined with a series of three other dyes 29-30 comprising the same electron acceptor (See Fig. 10) [69].

Synthesis of $\mathbf{C b z}_{-} \mathbf{3}$ proved to be more difficult than that of $\mathbf{C b z}_{-} \mathbf{1}$ and Cbz_2 since addition of a base (piperidine) was required to generate the anion of indane-1,3-dione 31. A reflux of $24 \mathrm{~h}$ in ethanol was also required to get the product in $86 \%$ yield (see Scheme 4). On the opposite, synthesis of $\mathbf{2 9}$ and $\mathbf{3 0}$ starting from the aldehydes $\mathbf{3 2}$ and $\mathbf{3 3}$ was easier, the different dyes being obtained with reaction yields ranging from 82 to $94 \%$ after only four hours of reflux.

Compared to $\mathrm{Cbz}_{-} \mathbf{1}$ and $\mathrm{Cbz}_{-} 2, \mathrm{Cbz}_{-} 3$ exhibited an absorption maximum located at $448 \mathrm{~nm}$ which is an intermediate situation between that of Cbz_1 (431 nm) and Cbz_2 (462 nm). Similarly, the molar extinction coefficient of $\mathrm{Cbz}_{-} 3\left(42000 \mathrm{M}^{-1} \cdot \mathrm{cm}^{-1}\right)$ is an intermediate situation between that of Cbz_1 (45 $\left.000 \mathrm{M}^{-1} \cdot \mathrm{cm}^{-1}\right)$ and $\mathrm{Cbz}_{-} 2\left(37000 \mathrm{M}^{-1} \cdot \mathrm{cm}^{-1}\right)$. Conversely, due to the weak electron donor, the absorption of 29 is UV-centered ( $351 \mathrm{~nm}, 29900 \mathrm{M}^{-1} \cdot \mathrm{cm}^{-1}$ ) whereas the absorption of 30 which possesses a stronger electron donor than 29 is centered in the visible range $\left(467 \mathrm{~nm}, 7700 \mathrm{M}^{-1} \cdot \mathrm{cm}^{-1}\right)$ but exhibit a low molar extinction coefficient. Once again, the crucial role of the electron donor on both the absorption maximum and the molar extinction coefficient was clearly evidenced. Polymerization of EPOX using the three-component system $\quad \mathrm{Cbz}_{-} 3 / \mathrm{NVK} / \mathrm{Ph}_{2} \mathrm{I}^{+} \quad(0.3 \% / 3 \% / 2 \% \quad \mathrm{w} / \mathrm{w})$ furnished a final monomer conversion of $59 \%$ after $800 \mathrm{~s}$ of irradiation with a laser diode at $457 \mathrm{~nm}\left(100 \mathrm{~mW} / \mathrm{cm}^{2}\right)$ under air. This result is similar to that obtained with $\mathbf{C b z}_{-} \mathbf{2}$ in the same conditions. While using a LED emitting at $385 \mathrm{~nm}$, a final monomer conversion of $61 \%$ could be determined after $1000 \mathrm{~s}$ of irradiation under air, resulting from the high molar extinction coefficient of $\mathrm{Cbz}_{-} 3$ at this wavelength $(\epsilon>10$ $000 \mathrm{M}^{-1} \cdot \mathrm{cm}^{-1}$ ). Overall, the polymerization can be efficiently initiated in the $350-450 \mathrm{~nm}$ range, even with light sources of low light intensity as in the case of the LED bulb emitting at $385 \mathrm{~nm}\left(9 \mathrm{~mW} / \mathrm{cm}^{2}\right)$. Comparison of the polymerization efficiencies of $\mathbf{2 9}$ and $\mathbf{3 0}$ in the same conditions revealed these two dyes to be unable to initiate the polymerization of EPOX. Finally, polymerization of TMPTA using the same three-component system Cbz_3/NVK/ $\mathrm{Ph}_{2} \mathrm{I}^{+}(0.3 \% / 3 \% / 2 \% \mathrm{w} / \mathrm{w})$ furnished a final monomer conversion of $58 \%$ while irradiating at $457 \mathrm{~nm}$. Considering that $\mathrm{Ph}-\mathrm{NVK}^{*}$ and $\mathrm{Ph}-\mathrm{NVK}^{+}$species are formed during polymerization, the concomitant cationic/radical photopolymerization of an EPOX/ TMPTA blend $(50 \% / 50 \% \mathrm{w} / \mathrm{w})$ under air and in laminate was examined (See Fig. 11).

As anticipated, under air, the FRP of TMPTA was inhibited by the presence of oxygen (See Fig. 11a). Besides, the final monomer conversion of $50 \%$ after 5 min highlights the remarkable photoinitiating ability of the Cbz_3-based system, this result being obtained with a LED at $462 \mathrm{~nm}$ of low light intensity $\left(10 \mathrm{~mW} / \mathrm{cm}^{2}\right)$. In laminates i.e. in oxygen-free conditions, the monomer conversion could be increased up to $70 \%$, producing tack-free polymers (See Fig. 11b).

Classically, thiol-ene photopolymerizations is carried out with UV light [105-108]. In the present case, the polymerization profiles ob-

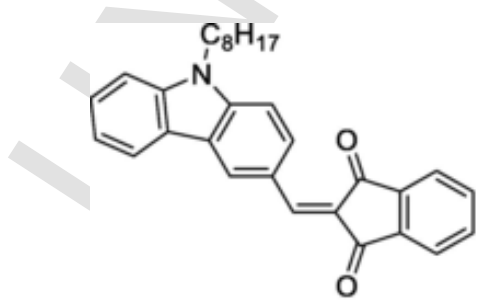

Cbz_3<smiles>CCCCCCCc1ccc(C=C2C(=O)c3ccccc3C2=O)cc1</smiles>

29<smiles>O=C1C(=Cc2c3ccccc3cc3ccccc23)C(=O)c2ccccc21</smiles>

30

Fig. 10. Chemical structures of $\mathrm{Cbz}_{-} 3$ and references compounds 29 and 30. 


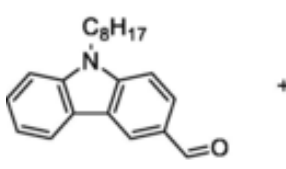

26<smiles>O=C1CC(=O)c2ccccc21</smiles>

31<smiles>O=C1CC(=O)c2ccccc21</smiles>

31

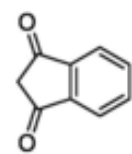

31

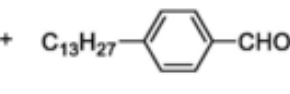

32

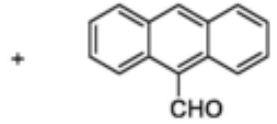

33

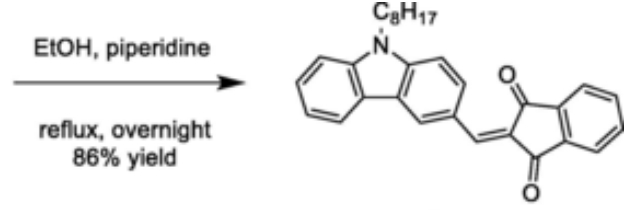

Cbz_3<smiles>CCCCCCCc1ccc(C=C2C(=O)c3ccccc3C2=O)cc1</smiles>

reflux, $4 \mathrm{~h}$
$94 \%$ yield
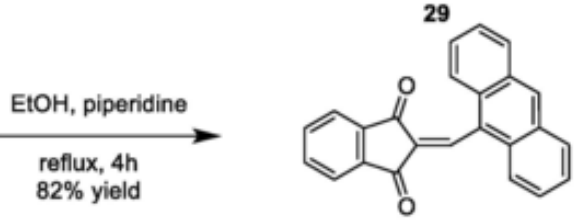

30

Scheme 4. Synthetic routes to $\mathrm{Cbz}_{-} 3$ and push-pull dyes 29 and 30
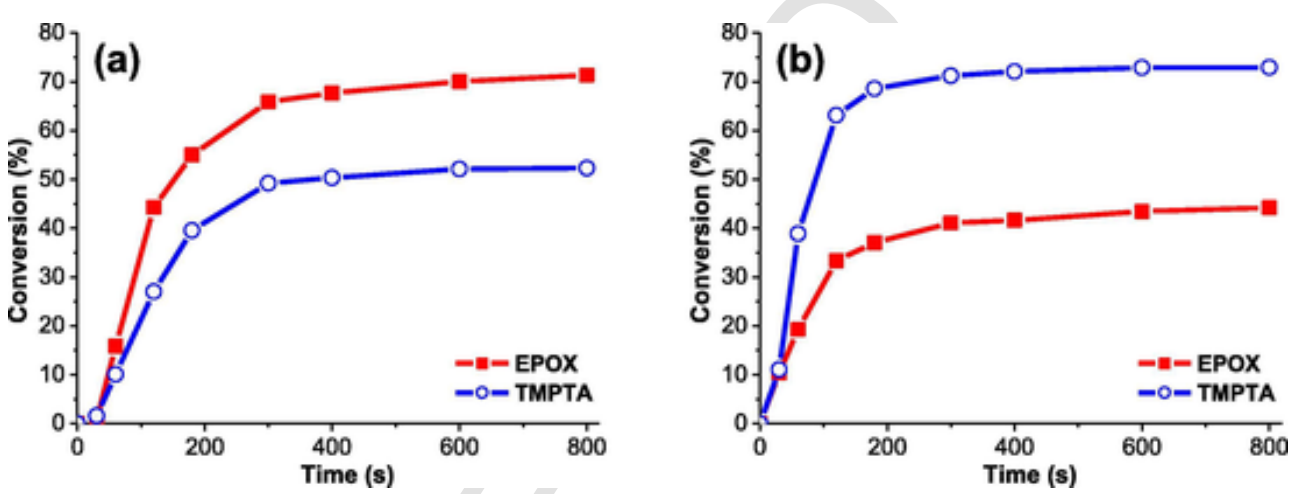

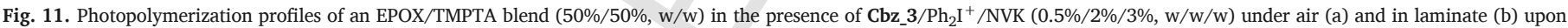
irradiation with a LED bulb at $462 \mathrm{~nm}$. Reproduced with permission from Xiao et al. [69]. Copyright 2014 American Chemical Society.

tained for the copolymerization of trithiol/DVE-3 upon irradiation with a laser diode at $457 \mathrm{~nm}\left(100 \mathrm{~mW} / \mathrm{cm}^{2}\right)$ or a LED bulb at $462 \mathrm{~nm}$ $\left(10 \mathrm{~mW} / \mathrm{cm}^{2}\right)$ were similar, even though the light intensity of the LED was 10 times lower than that of the laser diode (See Fig. 12). It therefore demonstrates the high reactivity of the two-component Cbz_3/ $\mathrm{Ph}_{2} \mathrm{I}^{+}$system. Samples with thickness ranging between 1 and $5 \mathrm{~nm}$ could also be polymerized using this approach.

In line of the mechanism proposed for the FRP of acrylates or the FRCPCP of epoxides (See before), the following mechanism was proposed to support the thiol-ene photopolymerization of the DVE-3/ trithiol blend. Notably, the phenyl radical $\mathrm{Ph}^{*}$ can induce a hydrogen abstraction from the thiol monomer, producing $\mathrm{RS}^{*}$ than can subsequently add onto the vinyl groups of DVE-3, initiating the polymerization process.

$$
\begin{aligned}
& \text { dye } \rightarrow{ }^{1} \text { dye }(h \nu) \\
& { }^{1} \text { dye }+\mathrm{Ph}_{2} \mathrm{I}^{+} \rightarrow \text { dye }{ }^{\cdot+}+\mathrm{Ph}_{2} \mathrm{I}^{\bullet} \\
& \mathrm{Ph}_{2} \mathrm{I}^{*} \rightarrow \mathrm{Ph}^{*}+\mathrm{Ph}-\mathrm{I} \\
& \mathrm{Ph}^{\bullet}+\mathrm{NVK} \rightarrow \mathrm{Ph}-\mathrm{NVK}^{\bullet} \\
& \text { Ph-NVK }{ }^{*}+\mathrm{Ph}_{2} \mathrm{I}^{+} \rightarrow \mathrm{Ph}^{-\mathrm{NVK}^{+}}+\mathrm{Ph}-\mathrm{I}+\mathrm{Ph}^{\bullet} \\
& \mathrm{Ph}-\mathrm{NVK}^{*}+\mathrm{Ph}_{2} \mathrm{I}^{+} \rightarrow \mathrm{Ph}^{-\mathrm{NVK}^{+}}+\mathrm{Ph}_{2} \mathrm{I}^{\bullet}
\end{aligned}
$$

$$
\begin{aligned}
& \mathrm{Ph}^{\bullet}+\mathrm{RS}-\mathrm{H} \rightarrow \mathrm{Ph}-\mathrm{H}+\mathrm{RS}^{\bullet} \\
& \mathrm{RS}^{\bullet}+\mathrm{R}^{\prime}-\mathrm{CH}=\mathrm{CH}_{2} \rightarrow \mathrm{R}^{\prime}-\mathrm{CH}^{\bullet}-\mathrm{CH}_{2} \mathrm{SR}
\end{aligned}
$$

While getting a deeper insight into the polymerization mechanism, examination of the photolysis of the $\mathrm{Cbz}_{-} 3 / \mathrm{Ph}_{2} \mathrm{I}^{+}$mixture in acetonitrile revealed the photobleaching to be relatively fast with this dye whereas no photobleaching was observed after $10 \mathrm{~min}$ for the $29 / \mathrm{Ph}_{2} \mathrm{I}^{+}$and 30/ $\mathrm{Ph}_{2} \mathrm{I}^{+}$mixtures (See Fig. 13). These results are consistent with a back electron-transfer in $\mathrm{r} 1$ and the poor efficiency observed in photopolymerization for these two dyes.

Finally, the possibility to incorporate Ag nanoparticles into EPOX and TMPTA-based polymers was examined as it can deeply modify the mechanical properties of the resulting polymers. To generate these nanoparticles, a silver salt i.e. $\mathrm{AgSbF}_{6}$ was used (See Fig. 14). Introduction of Ag nanoparticles was notably obtained by oxidation of $\mathrm{Ph}-\mathrm{NVK}{ }^{*}$ with this silver salt, reducing $\mathrm{Ag}^{+}$to $\mathrm{Ag}(0)$ according to the following equation:

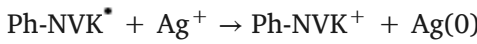

In 2017, carbazole was revisited in the context of a new approach where carbazole was not used as an electron donor but as a conjugated spacer connected electron-donating and accepting groups introducing on both sides of its skeleton. In this innovative approach, nitro, dialky- 
<smiles>C=COCCOCCOCCOC(=O)CCS</smiles>
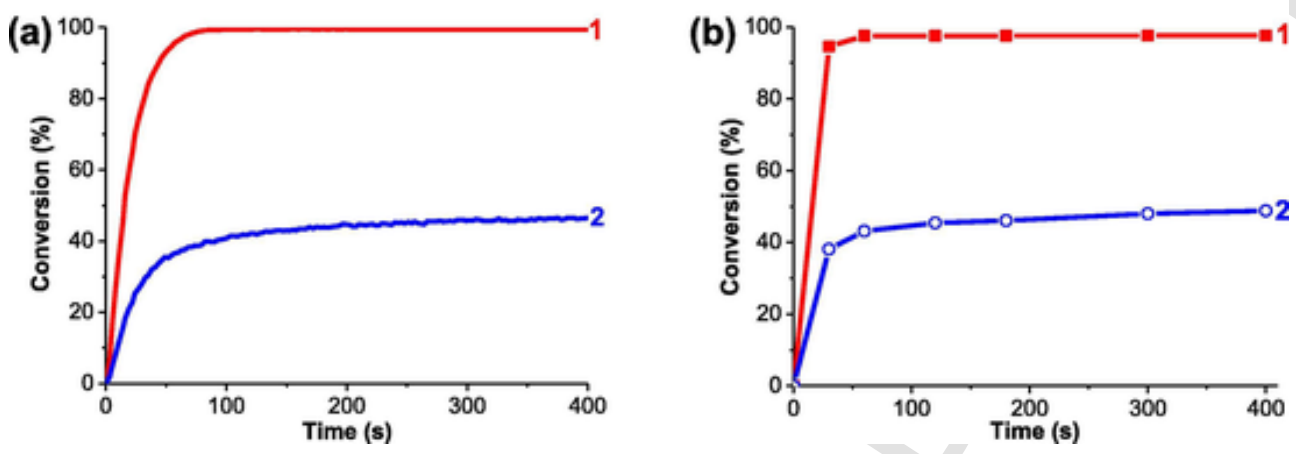

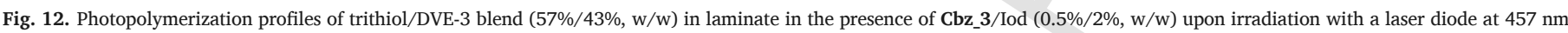

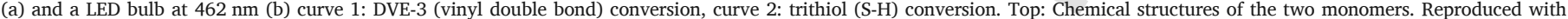
permission from Xiao et al. [69]. Copyright 2014 American Chemical Society.
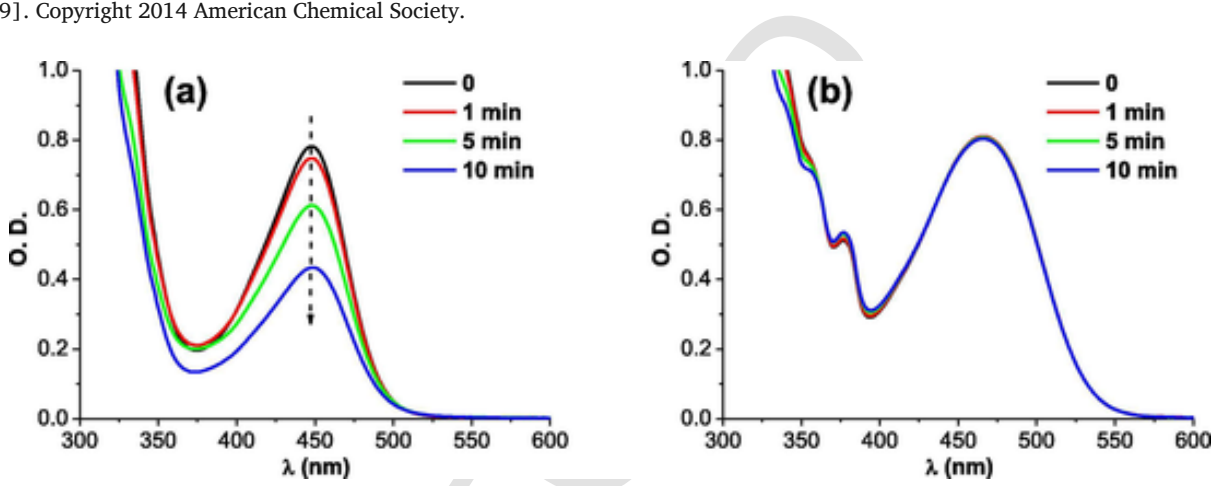

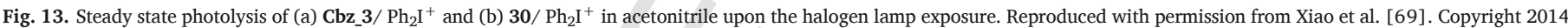
American Chemical Society.

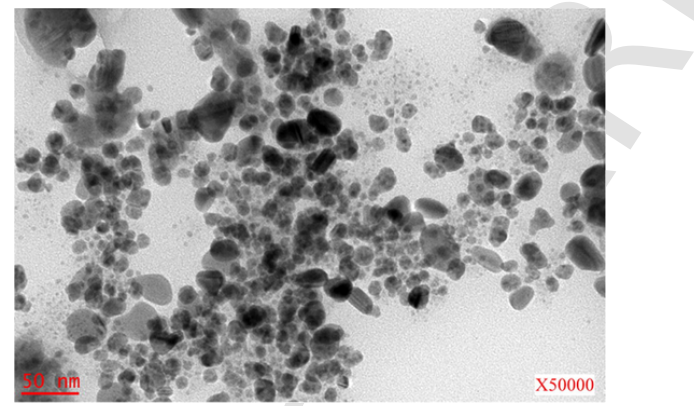

Fig. 14. TEM image for the polymerization of EPOX using the four-component system $\mathrm{Cbz}_{-} 3 / \mathrm{Ph}_{2} \mathrm{I}^{+} / \mathrm{NVK} / \mathrm{AgSbF}_{6}$ upon irradiation with a LED bulb at $462 \mathrm{~nm}$. Reproduced with permission from Xiao et al. [69]. Copyright 2014 American Chemical Society.

lamino and aldehyde groups were introduced as peripheral groups of Cbz_4-Cbz_7 (See Fig. 15) [109]. As specificity, the four carbazole derivatives $\mathrm{Cbz}_{-} 4-\mathrm{Cbz}-7$ could be used as photoredox catalysts so that low photoinitiator contents could be used. To evidence the validity of this approach, a comparison with two benchmark photoinitiators, namely bis(2,4,6-trimethylbenzoyl)phenylphosphine oxide (BAPO) and $9 H$-carbazole-9-ethanol (CARET) was established.

As first interesting feature, UV-visible absorption spectra of Cbz_4-Cbz-7 in dichloromethane revealed Cbz_7 to exhibit the most extended absorption, this latter ranging from 350 to $500 \mathrm{~nm}$. This broad absorption band can be assigned to the simultaneous presence of both the electron accepting nitro groups and the electron-donating alkylamino groups, inducing an efficient electronic delocalization. For the other dyes (Cbz_4-Cbz-6), an absorption extending between 350 and $440 \mathrm{~nm}$ was only found (See Fig. 16). Finally, comparison of the absorption spectra of Cbz_4-Cbz-7 with that of CARET and BAPO revealed the absorption of CARET to be inexistent between 360 and $550 \mathrm{~nm}$ whereas a low absorption was detected for BAPO between 350 and $450 \mathrm{~nm}$.

Interestingly, the two-component systems Cbz_4-Cbz_7 $/(t-\mathrm{Bu}) \mathrm{Ph}_{2} \mathrm{I}^{+}$ $(0.5 \% / 1 \% \mathrm{w} / \mathrm{w})$ showed a high reactivity for the polymerization of EPOX upon irradiation with a LED at $405 \mathrm{~nm}\left(110 \mathrm{~mW} / \mathrm{cm}^{2}\right)$ since final monomer conversions of 76, 50, 58 and $70 \%$ could be obtained with Cbz_4-Cbz_7 respectively. Interestingly, no direct correlation with the molar extinction coefficients and the monomer conversions was found, the best performances being obtained with the dye exhibiting the lowest absorption at $405 \mathrm{~nm}$. In fact, authors tentatively assigned the higher photoinitiating ability of $\mathbf{C b z}_{-} 4$ compared to $\mathbf{C b z}_{-} \mathbf{6}$ to the bulkiness of the octyl chain in $\mathbf{C b z} \mathbf{6}$, the two dyes only differing by the length of the alkyl chain on the central amine. During polymerization and the formation of the crosslinked polymer, the radical cation on $\mathbf{C b z}_{-} 4$ remains more available than that of $\mathbf{C b z}_{-} \mathbf{6}$ due to the smaller size of the alkyl chain, enabling to reach in turn higher final monomer conversions. Besides, in this work, the usual three-component systems $\mathbf{C b z}_{-} \mathbf{x}$ $(x=4-7) /(t-B u) \mathrm{Ph}_{2} \mathrm{I}^{+} / \mathrm{NVK}$ was not examined for the polymerization of EPOX, due to the exceptional efficacy of the two-component systems. 


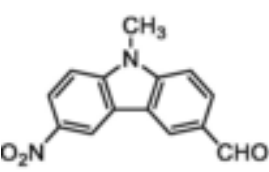

Cbz_4<smiles>Cn1c2ccccc2c2cc([N+](=O)[O-])ccc21</smiles>

Cbz_5<smiles>CCn1c2ccc(C=O)cc2c2cc([N+](=O)[O-])ccc21</smiles>

Cbz_6

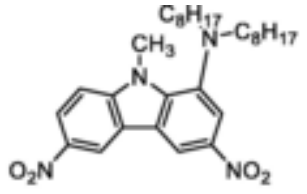

Cbz_7<smiles>Cc1cc(C)c(C(=O)P(=O)(C(=O)c2c(C)cc(C)cc2C)c2ccccc2)c(C)c1</smiles>

BAPO<smiles>CCOC(=O)c1ccc(N(C)C)cc1</smiles>

EDB<smiles>OCCn1c2ccccc2c2ccccc21</smiles>

CARET<smiles>CC(C)(C)c1ccc([Te]c2ccc(C(C)(C)C)cc2)cc1</smiles>

(t-Bu) $\mathrm{Ph}_{2} \mathrm{I}^{+}$<smiles>C=C(C)C(=O)OCC(O)COc1ccc(C(C)(C)c2ccc(OCC(O)COC(=O)C(=C)C)cc2)cc1</smiles><smiles>C=C(C)C(=O)OCCOCCOCCOC(=O)C(=C)C</smiles>

TEGDMA

Fig. 15. Chemical structures of Cbz_4-Cbz-7.

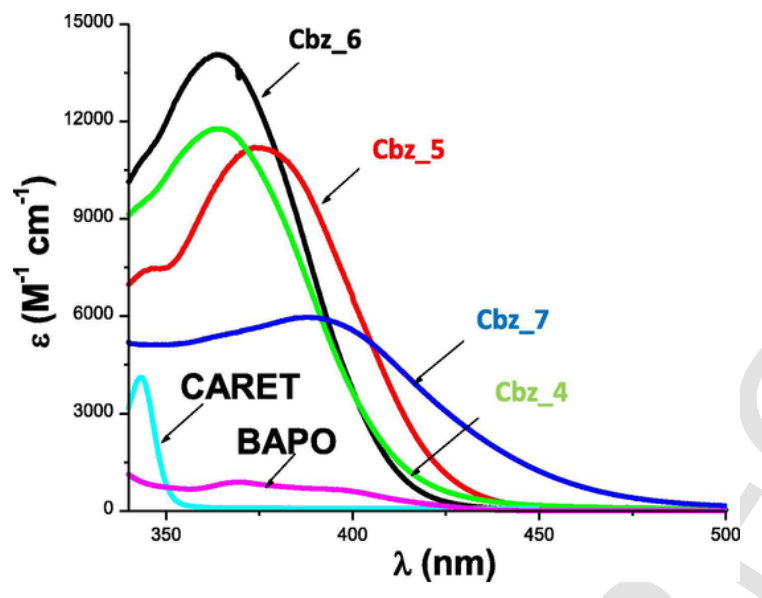

Fig. 16. Absorption spectra of the carbazole derivatives $\mathrm{Cbz}_{-} 4-\mathrm{Cbz}_{-} 7$ in $\mathrm{CH}_{3} \mathrm{CN}$, and BAPO in $\mathrm{CH}_{2} \mathrm{Cl}_{2}$. Reproduced with permission from Al Mousawi et al. [109]. Copyright 2017 American Chemical Society.

Compared to the final monomer conversions obtained with carbazoles Cbz_4-Cbz_7, the final conversion obtained with BAPO was extremely low, only peaking at $15 \%$. While decreasing the photoinitiator content from 1 to $0.5 \%$, an improvement of ca $8 \%$ for the monomer conversion of EPOX could be obtained with Cbz_6. This improvement can be confidently assigned to internal filter effects at high photoinitiator concentrations, this compound being particularly colored $[110,111]$. Face to the high reactivity of the two-component systems, surface patterning with an epoxide resin was carried out. By using a LED projector emitting at $405 \mathrm{~nm}\left(100 \mathrm{~mW} / \mathrm{cm}^{2}\right)$ and by using the two-component system Cbz_5/Iod $(0.5 \% / 1 \% \mathrm{w} / \mathrm{w})$, different structures of high resolution could be obtained, as shown in the Fig. 17.

Remarkable efficiencies were also obtained for the polymerization of TMPTA in laminates and similar monomer conversions were obtained with all dyes, peaking around $50 \%$. While examining the polymerization of a methacrylic resin i.e. the dental resin composed of a mixture of bisphenol A-glycidyl methacrylate (BisGMA) and triethylene glycol dimethacrylate (TEGDMA) in a $70 \% / 30 \% \mathrm{w} / \mathrm{w}$ ratio, a significant improvement of the monomer conversion was obtained upon addition of a sacrificial amine to the two-component system, namely ethyl 4-(dimethylamino)benzoate (EDB). While using the three-component system $\mathrm{Cbz}_{-} 5 /(t-\mathrm{Bu}) \mathrm{Ph}_{2} \mathrm{I}^{+} / \mathrm{EDB}(0.5 \% / 1 \% / 1 \%)$, the final monomer conversion could be increased up to $65 \%$ contrarily to $43 \%$ for the two-component system $\mathrm{Cbz}_{-} 5 /(t-\mathrm{Bu}) \mathrm{Ph}_{2} \mathrm{I}^{+}$upon irradiation with a diode at $455 \mathrm{~nm}$. Fluorescence quenching experiments carried out on the Cbz_5/EDB mixture revealed a fast quenching process, consistent with the formation of $\mathrm{EDB}^{*}$ capable to initiate the FRP of acrylates. In this context, based on the different photolysis experiments and due to the major enhancement of the final monomer conversion upon addition of EDB, authors concluded to the regeneration of the dye by oxidation of the sacrificial amine (See Scheme 5). Parallel to this, the excited dye can also react with EDB, producing $\mathrm{EDB}^{\circ}$. By mean of the coexisting oxidative and the reductive cycle, $\mathrm{Ar}^{\circ}$ and $\mathrm{EDB}^{\circ}$ are both generated, improving the initiation step and in turn the FRP of (meth)acrylates.

\subsection{Carbazoles of extended aromaticity}

Parallel to the design of push-pull dyes, another strategy developed with carbazoles consisted in improving the molar extinction coefficients by extending the aromaticity. If this strategy is efficient with regards to the molar extinction coefficient, it is also ineffective to red-shift the UV-centered absorption of carbazole towards the visible region. To illustrate this, substitution of carbazole with pyrene moieties enabled to produce Cbz_8 exhibiting a maximum absorption at $346 \mathrm{~nm}$ with a molar extinction coefficient of $55000 \mathrm{M}^{-1} \cdot \mathrm{cm}^{-1}$, therefore, greatly higher than what could be obtained with pure carbazole. Examination of its absorption spectrum also revealed this compound to strongly absorb between 300 and $410 \mathrm{~nm}$, the tail not extending beyond $410 \mathrm{~nm}$ (See Fig. 18).

On the opposite, $\mathbf{3 9}$ and $\mathbf{4 0}$ exhibit broader absorption spectra due to the simultaneous presence of three pyrene units, increasing the molar extinction coefficient. Interestingly, comparison of the photoinitiating abilities of Cbz_8 with that of a series of eleven pyrene-based photoinitiators 34-44 revealed once again the carbazole derivative $\mathbf{C b z}_{-} \mathbf{8}$ to outperform the others (See Fig. 19) [52].

While polymerizing EPOX with a Xe-Hg lamp and two-component photoinitiating systems dye/Iod $(0.2 \% / 2 \% \mathrm{w} / \mathrm{w})$ based on $\mathrm{Cbz}_{-} 8$ or 34-44 and where Iod stands for [methyl-4-phenyl (methyl-1-ethyl)-4-phenyl] iodonium tetrakis(pentafluorophenyl)borate (Iod), a final monomer conversion of $86 \%$ could be obtained with Cbz_8 after $200 \mathrm{~s}$ of irradiation, higher than that obtained with 36 (78\%) and significantly higher than that obtained with pyrene 34 (50\%) used in this study as the reference compound. Considering that the eleven dyes 

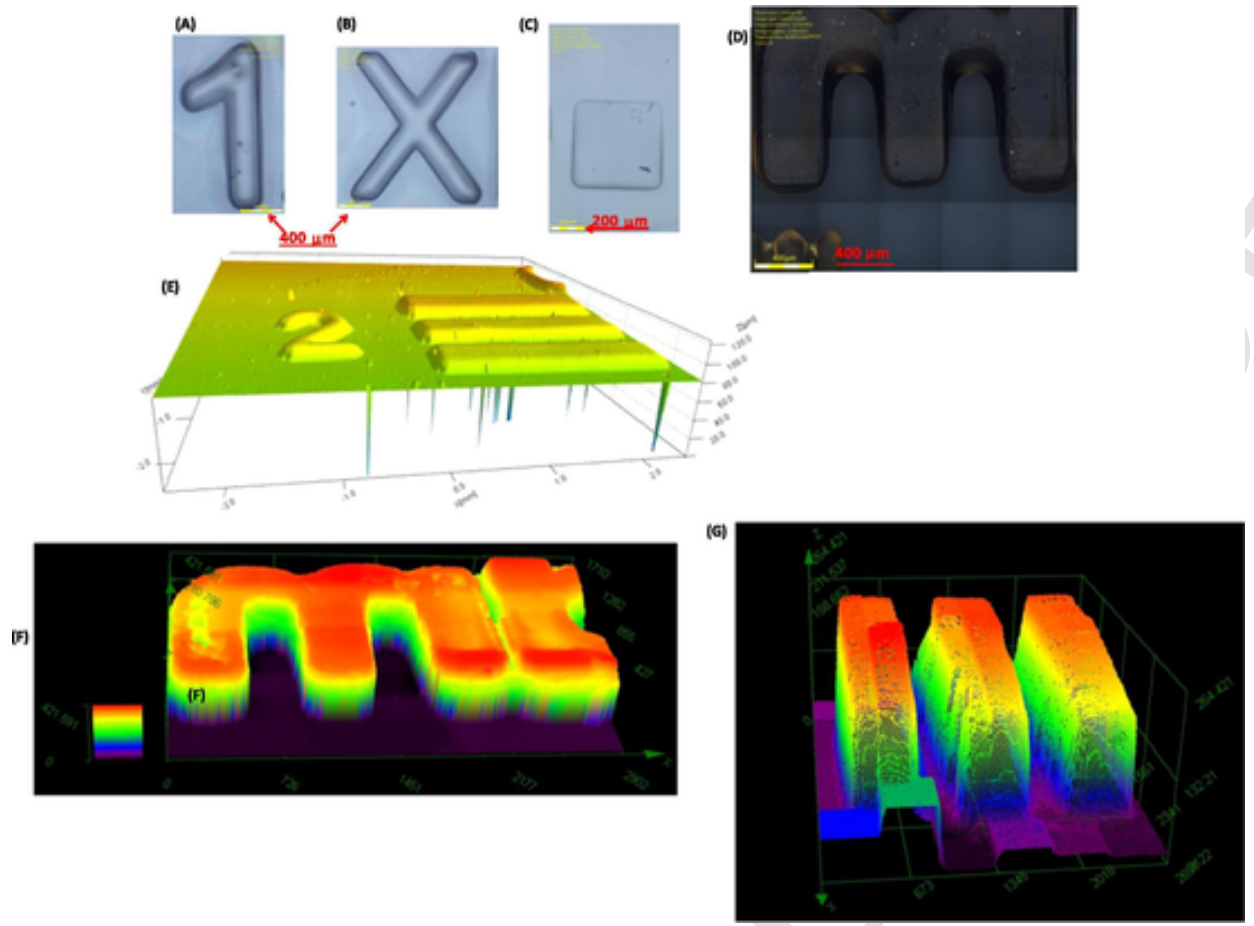

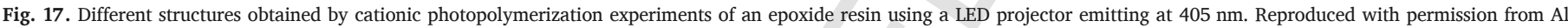
Mousawi et al. [109]. Copyright 2017 American Chemical Society.

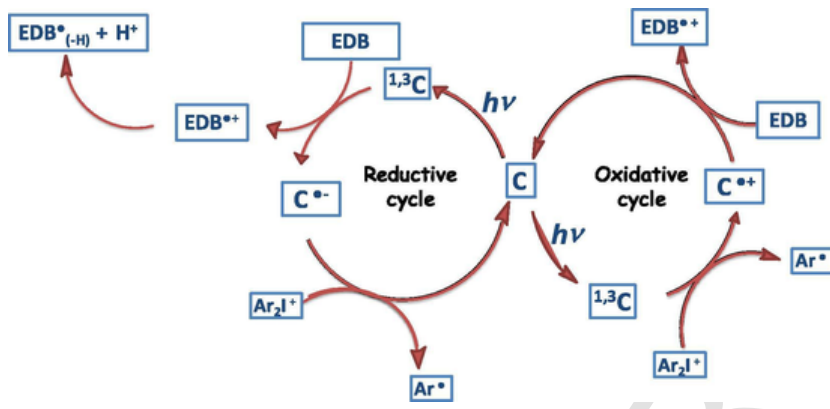

Scheme 5. Catalytic cycles enabling the regeneration of the carbazole-based dye upon addition of EDB. Reproduced with permission from Al Mousawi et al. [109]. Copyright 2017 American Chemical Society.

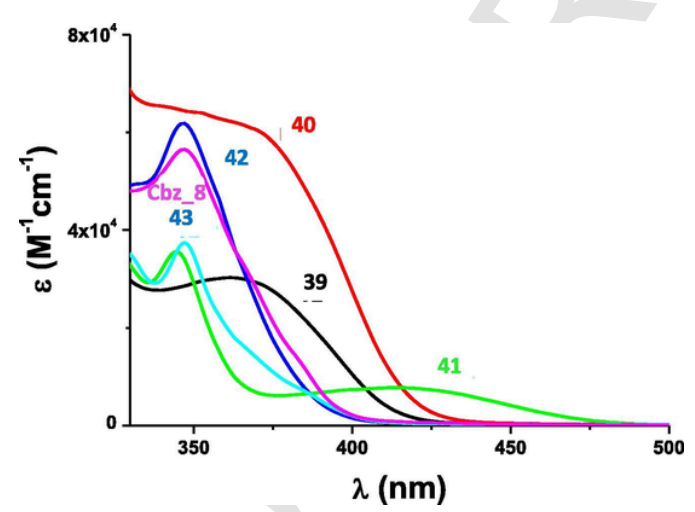

Fig. 18. UV-visible absorption spectra of $\mathrm{Cbz}_{-} 8,39-43$ in toluene. Reproduced with permission from Telitel et al. [52]. Copyright 2013 Beilstein J. Org. Chem.

derivatives of pyrene 34 , the major differences of photoinitiating abilities of Cbz_8, 35-44 compared to that 34 evidenced the interest of modifying this benchmark photoinitiator. However, in this work, no clear trend could be established concerning the structure-performance relationship. Notably, polymerization performances are the result of a subtle interplay between molar extinction coefficients, excited state lifetimes and the rate constants of interaction hetween Iod and the dye (see equation below) and the ability of the dye $\mathbf{e}^{+}$to initiate a ring-opening polymerization process.

${ }^{1}$ Dye $+\operatorname{Iod}\left(\mathrm{Ar}_{2} \mathrm{I}^{+}\right) \rightarrow \mathrm{Dye}^{\bullet+}+\mathrm{ArI}+\mathrm{Ar}^{\bullet}$

While using a halogen lamp emitting beyond $380 \mathrm{~nm}$, a final monomer conversion of 55\% could be determined for EPOX with the two-component system Cbz_8/Iod $(0.2 \% / 2 \% \mathrm{w} / \mathrm{w})$, what could be increased up to $75 \%$ with the three-component system Cbz_8/Iod/NVK $(0.2 \% / 2 \% / 2 \% \mathrm{w} / \mathrm{w})$. This remarkable monomer conversion is notably attributable to the photocatalytic behavior of the three-component system with the formation of the highly reactive $\mathrm{Ar}-\mathrm{NVK}^{*}$. Surprisingly, a low storage stability was found for the resins based on the two-component systems dye/Iod $(1 \% / 2 \% \mathrm{w} / \mathrm{w})$ and incorporating 39, 42, 43 and Cbz_8. For these resins, a thermal polymerization occurring at room temperature could be evidenced and after $24 \mathrm{~h}$ of storage, a complete polymerization of the monomer was demonstrated. This unwanted polymerization at room temperature and in the dark constitutes a severe limitation of the future use of these pyrene derivatives as photoinitiators.

More stable formulations were obtained with the Cbz_9-Cbz_15 series which differ from the previous one by the substitution pattern (See Fig. 20) [112]. In this work, an extension of conjugation by mean of a double bond was proposed to enhance the molar extinction coefficients while maintaining the absorption in the $300-400 \mathrm{~nm}$ region by the lack of intramolecular push-pull effects. Using this strategy, the molar extinction coefficient of $\mathbf{C b z}_{\mathbf{1}} \mathbf{1 3}$ could be increased up to $35000 \mathrm{M}^{-1} \cdot \mathrm{cm}^{-1}$ at $340 \mathrm{~nm}$, far from that of $9 H$-carbazole-9-ethanol (CARET) $\left(4000 \mathrm{M}^{-1} \cdot \mathrm{cm}^{-1}\right.$ at $\left.340 \mathrm{~nm}\right)$. Benefiting from a significant absorption at $405 \mathrm{~nm}, \quad$ Cbz_$_{-} \mathbf{( 1 0 0 0 \mathrm { M } ^ { - 1 } \cdot \mathrm { cm } ^ { - 1 } )}$ and Cbz_15 $\left(1000 \mathrm{M}^{-1} \cdot \mathrm{cm}^{-1}\right)$ could outperform BAPO $\left(500 \mathrm{M}^{-1} \cdot \mathrm{cm}^{-1}\right)$ for the polymerization of EPOX (44\% of monomer conversion after $200 \mathrm{~s}$ of irradiation for $\mathbf{C b z}_{-} \mathbf{9}$ and $\mathbf{C b z}_{-} \mathbf{1 5}$ contrarily to $15 \%$ of conversion with 


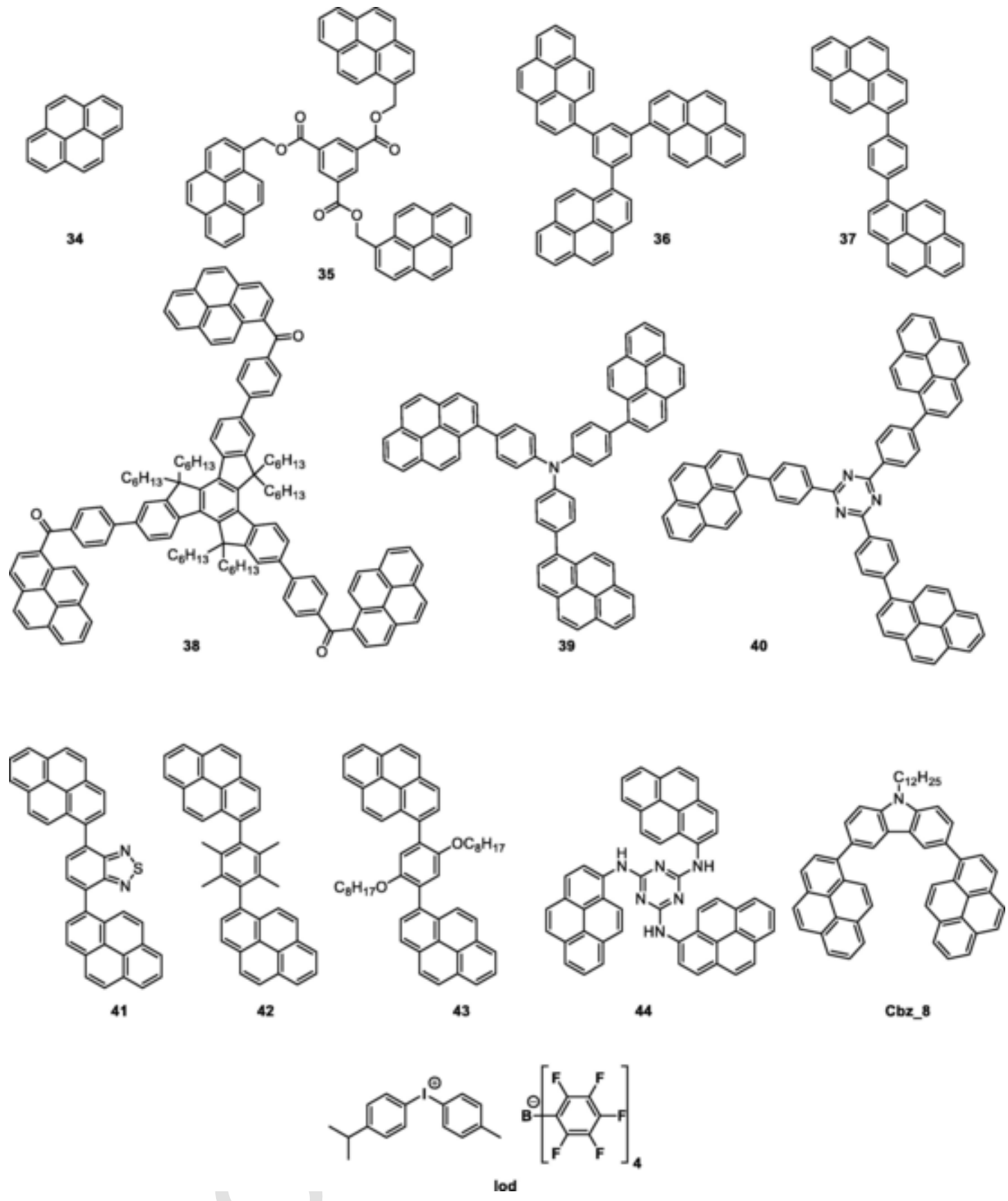

Fig. 19. Chemical structure of $\mathrm{Cbz}_{-} 8$ and 34-44.

BAPO) using a two-component system $\mathrm{Cbz}_{-} \mathbf{x}(\mathrm{x}=\mathbf{9},-15) /(t-\mathrm{Bu}) \mathrm{Ph}_{2} \mathrm{I}^{+}$ (0.5\%/1\% w/w) (See Fig. 21).

The superiority of $\mathbf{C b z} \mathbf{1 5}$ over the other carbazoles of this series was revealed during the FRP of acrylates. Upon irradiation with a LED at $405 \mathrm{~nm}$, a final conversion of $57 \%$ was determined with the two component system Cbz_15/( $t$-Bu) $\mathrm{Ph}_{2} \mathrm{I}^{+}(0.5 \% / 1 \% \mathrm{w} / \mathrm{w})$ after $100 \mathrm{~s}$ of irradiation. Conversely, a final conversion of only $46 \%$ was obtained in the same conditions with $\mathbf{C b z}_{-} \mathbf{9}$, attributable to a lower electron transfer quantum yield with $(t-\mathrm{Bu}) \mathrm{Ph}_{2} \mathrm{I}^{+}$. Besides, the order of reactivity determined during the $\mathrm{CP}$ of epoxides was confirmed with the FRP of acrylates. Interestingly, due to the lack of push-pull effects within Cbz_9-Cbz_15, colorless polymer films could be obtained with these different photoinitiators (See Fig. 21).

Finally, during the polymerization of the TMPTA/EPOX blend with the two component system $\mathbf{C b z}_{-} \mathbf{1 5} /(\mathrm{t}-\mathrm{Bu}) \mathrm{Ph}_{2} \mathrm{I}^{+}(0.5 \% / 1 \% \mathrm{w} / \mathrm{w})$, fi- nally monomer conversions of 76 and $23 \%$ were respectively determined for the conversion of TMPTA and EPOX. The three-fold enhancement of the TMPTA conversion relative to that of EPOX was assigned to the higher reactivity of the radicals compared to the cationic species [113]. Similar conclusions concerning CP and FRP could be established with another series of carbazole derivatives $\mathbf{C b z}_{-} \mathbf{1 6}-\mathbf{C b z}_{-} \mathbf{2 1}$ (See Fig. 22) [114]. Here again, the higher final monomer conversions obtained with $\mathbf{C b z}_{-} 17$ and $\mathrm{Cbz}_{-} 20$ during the FRP of acrylate or the FRPCP of epoxides was directly related their higher molar extinction coefficients. Interestingly, the best performances were obtained with the carbazoles substituted with an aldehyde function. In this case, a small electronic delocalization exists between the nitrogen and the aldehyde function, inducing a small push-pull effect and thus enhancing the absorption. 


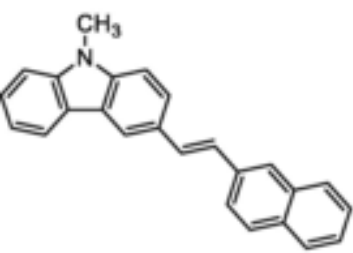

Cbz_9

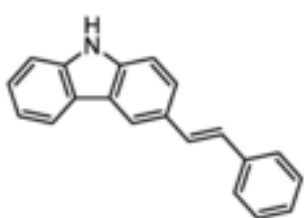

Cbz_10

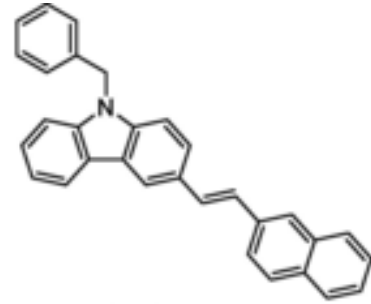

Cbz_11

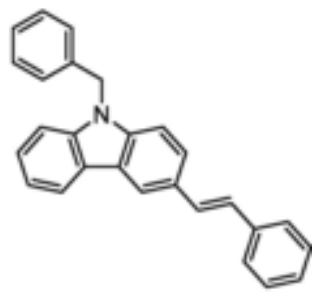

Cbz_12<smiles>Brc1ccc(/C=C/c2ccc3c(c2)c2ccccc2n3Cc2ccccc2)cc1</smiles>

Cbz_13

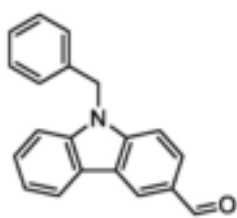

Cbz_14

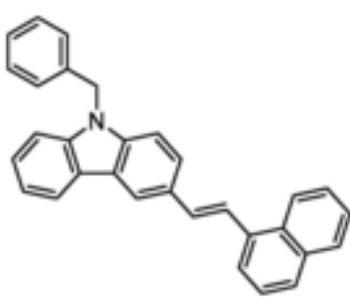

Cbz_15

Fig. 20. Chemical structures of the Cbz_9-Cbz_15 series.
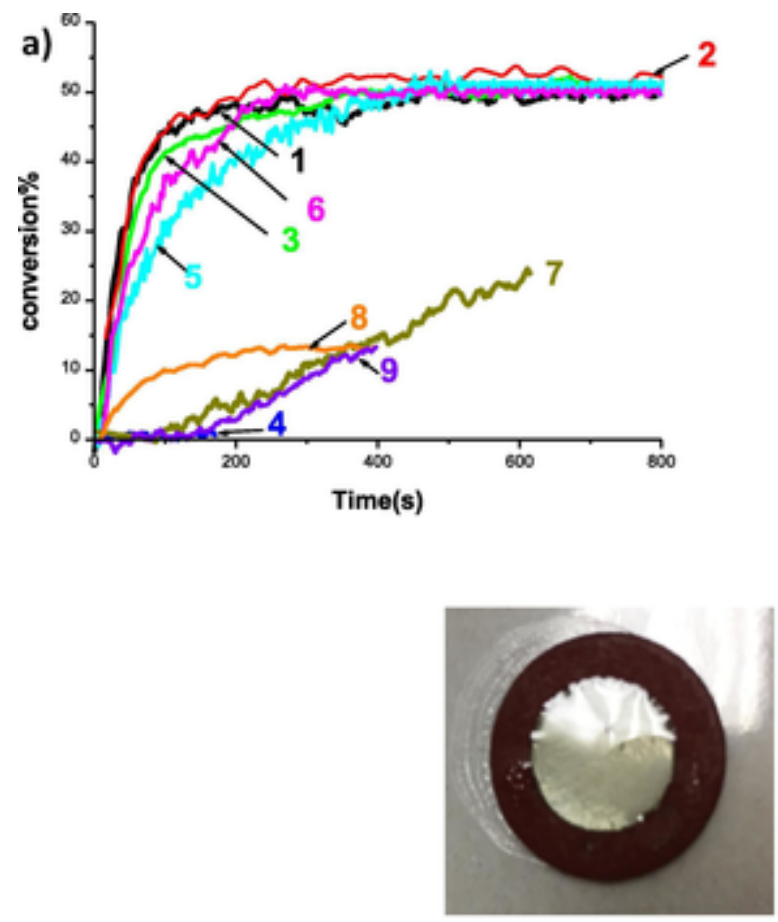

c) Before polymerization
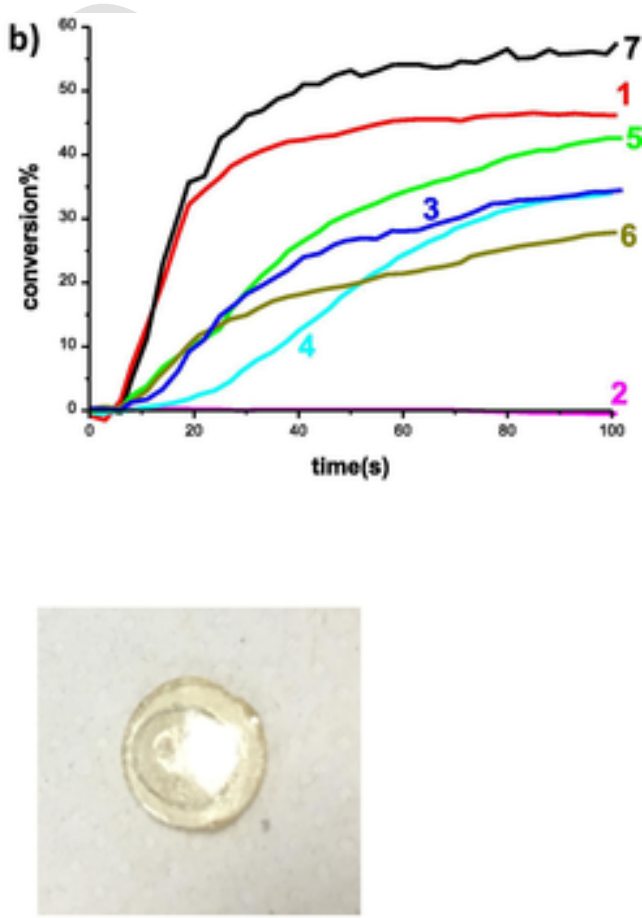

After polymerization

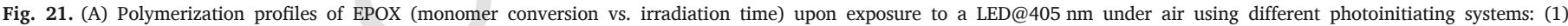

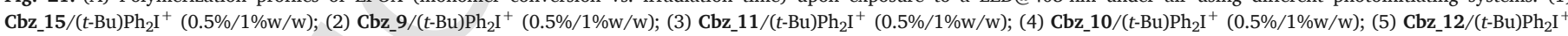

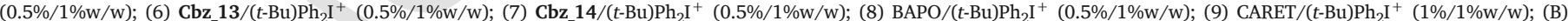

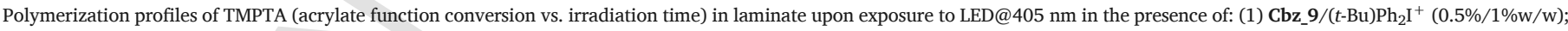

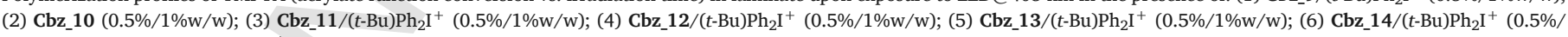

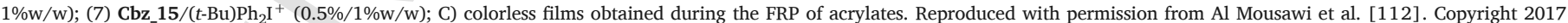
MDPI.

To extend the $\pi$-conjugation, another strategy consisted in introducing electron donating groups such as triphenylamine as peripheral groups of carbazole [115]. In this case, the adjunction of electron-donating groups to an electron donor cannot induce a push-pull effect within the molecules, no electronic interaction being possible between electron donors. As a consequence of this, the absorption positions of Cbz_22 and $\mathbf{C b z}_{-} 23$ were not significantly modified compared to that of an unsubstituted carbazole whereas an enhancement of the absorption coefficients could be obtained for the two dyes. By the presence of the numerous aromatic rings in $\mathrm{Cbz}_{-} 22$ and $\mathrm{Cbz}_{-} 23$, increase of the molar extinction coefficients resulted an absorption that became not negligible in the $400-450 \mathrm{~nm}$ region for $\mathrm{Cbz}_{-} 22$ and $\mathrm{Cbz}_{-} 23$ so that a polymerization process could be initiated for irradiations occurring beyond $400 \mathrm{~nm}$. As other specificity, $\mathbf{C b z}_{-} 22$ and $\mathbf{C b z} \_23$ were designed 
<smiles>CCOC(CN(Cc1cc(C)c2c(c1C)c1ccccc1n2C)S(=O)(=O)c1ccc(C)cc1)OCC</smiles>

Cbz_16<smiles>Cc1cc(C=O)c(C)c2c1c1ccccc1n2C</smiles>

Cbz_20<smiles>Cc1cc(C=O)c(C)c2c1[nH]c1ccccc12</smiles>

Cbz_17<smiles>Cc1ccc(C)c2c1c1ccccc1n2C=O</smiles><smiles>CCOC(CNCc1cc(C)c2c(c1C)c1ccccc1n2C)OCC</smiles>

Cbz_18 Cbz_19<smiles>CCOC(CN(Cc1cc(C)c2[nH]c3ccccc3c2c1C)S(=O)(=O)c1ccc(C)cc1)OCC</smiles><smiles>COc1ccc(N(c2ccc(OC)cc2)c2ccc3c(c2)c2cc(N(c4ccc(OC)cc4)c4ccc(OC)cc4)ccc2n3Cc2ccc(C)cc2)cc1</smiles><smiles>Cn1c2ccccc2c2cc(COCC3CO3)ccc21</smiles>

Cbz_24<smiles>c1ccc2c(c1)c1ccccc1n2CCOCC1CO1</smiles>

Cbz_25

Cbz_23

Fig. 22. Chemical structures of the $\mathrm{Cbz}_{-} 16-\mathrm{Cbz}_{-} 25$ series.

as non-extractible photoinitiators by introducing polymerizable groups such as styrene or vinylic groups in $\mathbf{C b z}_{-} 22$ and $\mathbf{C b z}_{-} 23$ respectively (See Fig. 22). Introduction of polymerizable functions on carbazole is not new and carbazole specifically designed for the FRPCP of epoxides was previously reported in 2009, possessing in this case oxiranes groups (Cbz_24 and Cbz_25) [116]. By carefully selecting the two component photoinitiating systems and by replacing $(t-\mathrm{Bu}) \mathrm{Ph}_{2} \mathrm{I}^{+}$by $N$-phenylglycine (NPG), colorless polymers could be obtained by polymerizing a BisGMA/TEGDMA blend under air at $405 \mathrm{~nm}$ using Cbz_22 and Cbz_23. Especially, an enhancement by about $20 \%$ of the monomer conversion was obtained by replacing $(t-\mathrm{Bu}) \mathrm{Ph}_{2} \mathrm{I}^{+}$by $N$-phenylglycine in the two-component systems (See Fig. 23).

Finally, the access to photocomposites was also examined. Indeed, by introducing glass fibers into the polymer network (50\% glass fibers/ $50 \%$ resin $\mathrm{w} / \mathrm{w}$ ), the mechanical properties of the final polymers can be greatly modified. If this specific point was not examined in this study, a proof of concept was done while using $\mathbf{C b z}_{-} 23$ in the two-component system Cbz_23 /NPG (0.5\%/1\% w/w).

In 2010, Yagci and coworkers proposed to fuse within a unique structure two efficient photoinitiators, namely the carbazole core to the thioxanthone moiety [117]. Thioxanthone is a standard type II photoinitiator extensively studied in the literature [118-121] and used in

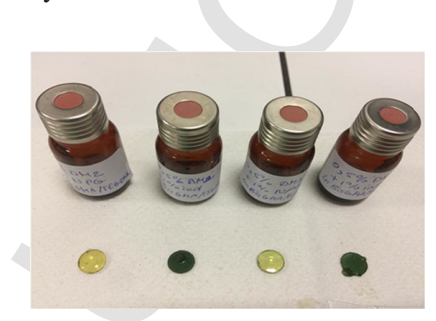

Fig. 23. Photographs of a BisGMA/TEGDMA thick film $(1.4 \mathrm{~mm})$ upon irradiation with

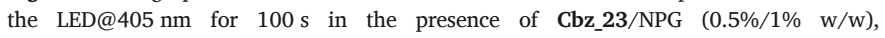
$\mathrm{Cbz}_{-} 23 /\left(t-{\mathrm{Bu}) \mathrm{Ph}_{2} \mathrm{I}^{+}}^{+} \quad(0.5 \% / 1 \% \quad \mathrm{w} / \mathrm{w}), \quad \mathrm{Cbz}_{-} 22 / \mathrm{NPG} \quad(0.5 \% / 1 \% \quad \mathrm{w} / \mathrm{w}) \quad\right.$ and $\mathrm{Cbz}_{-} 22 /(t-\mathrm{Bu}) \mathrm{Ph}_{2} \mathrm{I}^{+}(0.5 \% / 1 \% \mathrm{w} / \mathrm{w})$, respectively (from left to right), under air after polymerization. Reproduced with permission from Al Mousawi et al. [112]. Copyright 2017 MDPI. combination with numerous hydrogen donors such as alcohols, [122] thiols [123], ethers [124] or amines [125,126]. When thioxanthones are substituted with thiols [127-129] or carboxylic groups [130-132], photopolymerization without coinitiators became possible, these photoinitiators already containing hydrogen donors. This is in this context that Cbz_26 was developed, possessing a NH group onto carbazole. From a synthetic point of view, Cbz_26 could be prepared in $21 \%$ yield, by reacting carbazole 45 with thiosalicylic acid 46 in concentrated sulfuric acid (See Scheme 6).

Compared to carbazole and thioxanthone considered separately, an improvement of the molar extinction coefficient associated with a redshift of the maximum absorption was demonstrated in solution. Notably, a shift of $100 \mathrm{~nm}$ was observed between thioxanthone and Cbz_26. Photolysis experiments with and without hydrogen donors proved the carbazole moiety to act as a hydrogen donor so that the following mechanism described in Scheme 7 could be proposed to support the FRP of methacrylates. In the absence of external hydrogen donors, Cbz_26 - is the initiating species, what could be demonstrated by examining the photoluminescence of the poly(methyl methacrylate) (Poly(MMA)). Indeed, in this last case, $\mathbf{C b z} \mathbf{2 6}$ is connected to the polymer as the end group. A low inhibition to oxygen was demonstrated during the FRP of MMA, resulting from the hydrogen donor directly connected to the initiating radical. Benefiting from this, the FRP could be initiated even with photoinitiator concentration as low as $1 \times 10^{-3} \mathrm{M}$. Besides, if the concept is appealing, comparison of the photoinitiating ability of Cbz_26 with that of camphorquinone in the same conditions revealed camphorquinone to outperform $\mathrm{Cbz}_{\mathbf{2}} \mathbf{2 6}$, whatever the experimental conditions were.

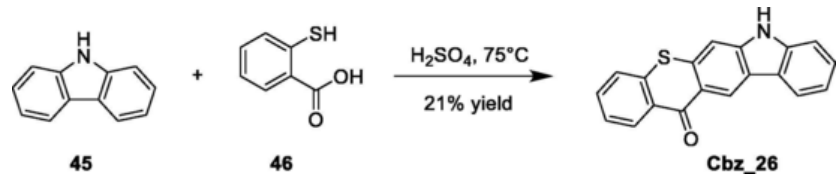

Scheme 6. Synthetic route to $\mathrm{Cbz}_{-} 26$. 

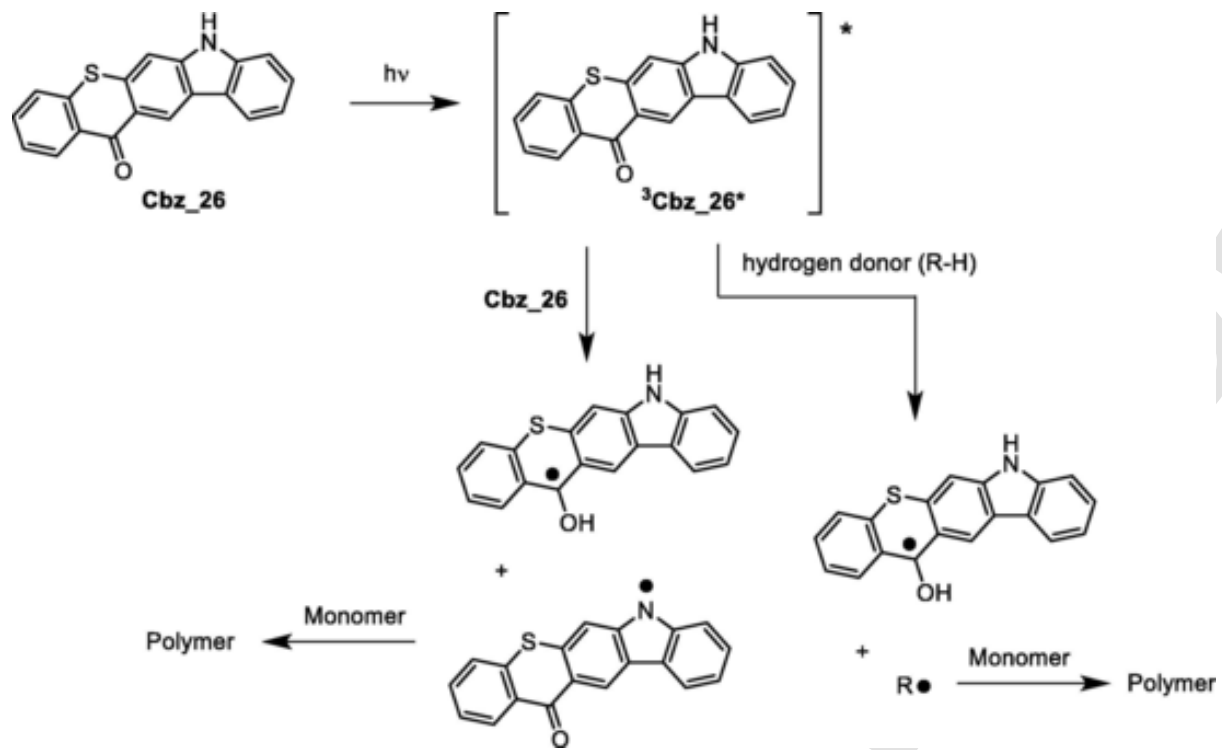

Scheme 7. The two possible photoinitiating systems with and without hydrogen donors using Cbz_26 as the photosensitizer.

\subsection{Carbazole-based TADF photoinitiators}

As previously mentioned, the photoinitiating ability of type II photoinitiators is directly related to their excited state lifetimes. Indeed, long-living excited states lifetimes favor intermolecular interactions of the photoinitiator with the different additives, optimizing the generation of initiating species. In 2012, Chihaya Adachi developed an innovative approach to improve the photoluminescence quantum yields (PLQY) of organic and organometallic compounds used in organic light-emitting diodes (OLEDs) $[133,134]$. By introducing sterically demanding groups around a central core, the Highest Occupied Molecular Orbital (HOMO) and the Lowest Unoccupied Molecular Orbital (LUMO) could be isolated from each other by interrupting the $\pi$-conjugation. By carefully selecting the electron donating and electron-accepting groups, compounds exhibiting a small energy splitting between the singlet and the triplet excited state could be obtained. As a result of this small energy $S_{1}-T_{1}$ splitting existing within these compounds, electrons from the triplet state can be up-converted to the singlet one, inducing a thermally activated delayed fluorescence process. Beyond the simple enhancement of the PLQY which is valorized in OLEDs, another parameter evidencing the presence of a Thermally Activated Delayed Fluorescence (TADF) property is a significant elongation of the excited state lifetime. Considering that the increase of the $S_{1}$ lifetime remains a chal- lenge in photochemistry, in 2017, this TADF property was exploited for the design of photoinitiators. In this work, a fine tuning of the excited state lifetimes could be obtained upon bromination of the peripheral carbazoles of the Cbz_27-Cbz_30 series (See Fig. 24) [135].

Thus, introduction of bromine onto carbazoles enabled to drastic elongate the excited state lifetimes under nitrogen, from $1.9 \mu \mathrm{s}$ for Cbz_27 to $4.8 \mu \mathrm{s}$ for $\mathbf{C b z}_{-} 30$, from $7.2 \mu \mathrm{s}$ for $\mathbf{C b z}_{-} 29$ to $7.8 \mu \mathrm{s}$ for Cbz_28 respectively. Parallel to this, by introducing cyano groups on Cbz_27 and $\mathrm{Cbz}_{-} 30$, energy level of the LUMO orbital could be lowered, thereby redshifting the absorption of these two compounds relative to $\mathrm{Cbz}_{-} 29$ and $\mathrm{Cbz}_{-} 28$. FRPCP of EPOX using a two-component

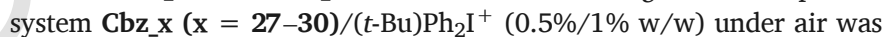
characterized by high polymerization rates and high final monomer conversions (47-55\%) both upon irradiation at 405 and $455 \mathrm{~nm}$. In the same conditions, CARET and BAPO which are two benchmark photoinitiators could only furnish a final monomer conversion of 12 and $15 \%$ after $400 \mathrm{~s}$ of irradiation at $405 \mathrm{~nm}$. At $455 \mathrm{~nm}$, no polymerization could even be initiated with these two references as a result of a lack of absorption for these two compounds. Considering that CARET is also a carbazole derivative, all the benefits of the chemical engineering in $\mathbf{C b z}$ 27-Cbz-30 was demonstrated in terms of polymerization performances.

Concerning the FRP of TMPTA, a photoredox catalyst behavior could be demonstrated with all TADF photoinitiators while using a three-component system $\mathrm{Cbz}_{-} \mathbf{x} \quad(\mathrm{x}=\mathbf{2 7}-\mathbf{3 0}) /(t-\mathrm{Bu}) \mathrm{Ph}_{2} \mathrm{I}^{+} / \mathrm{EDB} \quad(0.5 \% /$

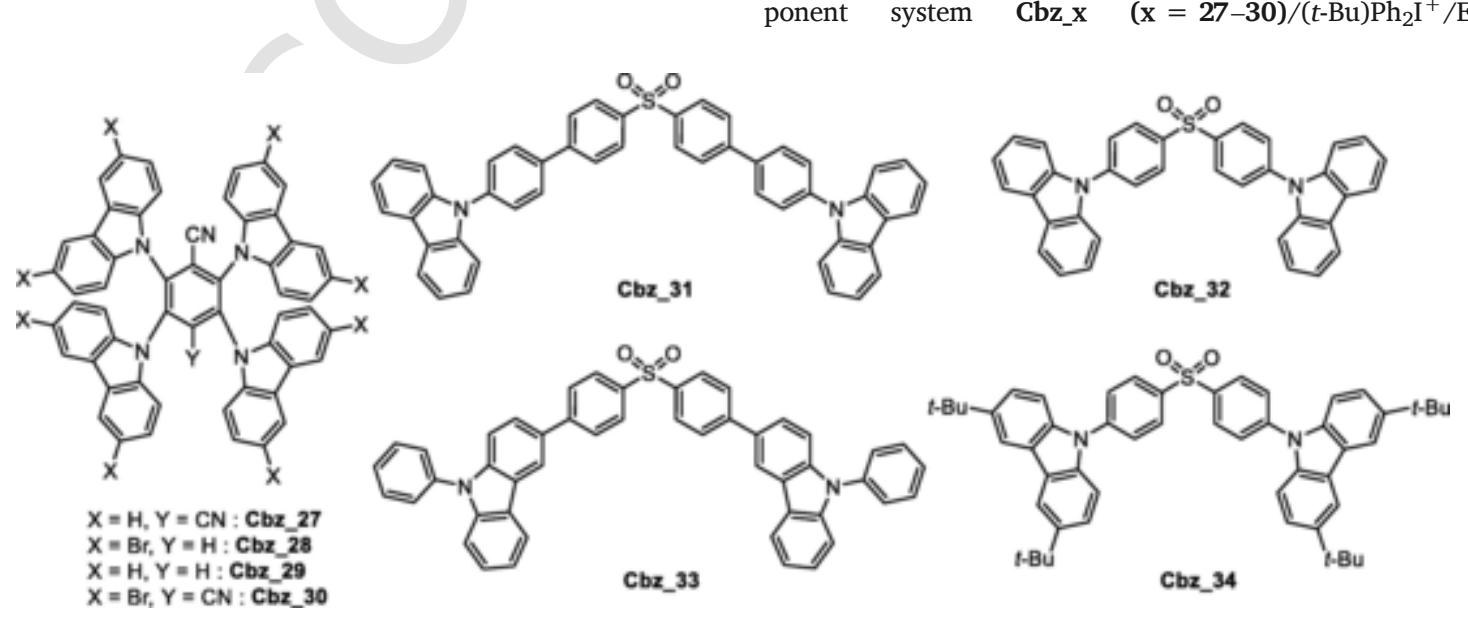

Fig. 24. Chemical structures of Cbz_27-Cbz_34. 
$1 \% / 1 \% \mathrm{w} / \mathrm{w})$. Finally, examination of the polymerization of a BISGMA/ TEGDMA blend (70/30) with the best photoinitiator i.e. Cbz_28 could provide tack-free and colorless polymers within $100 \mathrm{~s}$ with a monomer conversion of $60 \%$ upon irradiation with a LED at $405 \mathrm{~nm}$ under air. Conversely, at $477 \mathrm{~nm}$, the monomer conversion remained low (around 5\%) due to the lack of absorption for $\mathbf{C b z} 28$ (see Fig. 25).

While getting a deeper insight into the mechanism, the ability of Cbz_27-Cbz-30 to act as electron acceptors in the $\mathbf{C b z}_{-} \mathbf{x}$ ( $x=27-30) / E D B$ two-component photoinitiating system or as electron

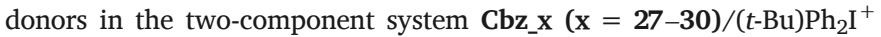
could be easily demonstrated by the fluorescence quenching experiments, the oxidation or the reduction of the photoinitiators resulting in the formation of none-luminescent compounds. Consequently, in the $\mathrm{Cbz}_{-} \mathrm{x}(\mathrm{x}=\mathbf{2 7 - 3 0}) /(t-\mathrm{Bu}) \mathrm{Ph}_{2} \mathrm{I}^{+} / \mathrm{EDB}$ three-component systems, a competition between the two routes exists and the two processes also occur simultaneously, the electron transfer quantum yields between $\mathrm{Cbz}_{-} \mathrm{x}(\mathrm{x}=27-30) /(t-\mathrm{Bu}) \mathrm{Ph}_{2} \mathrm{I}^{+}$or $\mathrm{Cbz}_{-} \mathrm{x}(\mathrm{x}=27-30) / \mathrm{EDB}$ being similar. Due to the concomitant regeneration of Cbz 27-Cbz-30 in both the oxidative and the reductive cycle, the improved efficiency of the three component systems over the two components systems $\mathbf{C b z} \mathbf{x}$ $(\mathrm{x}=27-30) /(t-\mathrm{Bu}) \mathrm{Ph}_{2} \mathrm{I}^{+}$or $\mathrm{Cbz}_{-} \mathrm{x}(\mathrm{x}=27-30) / \mathrm{EDB}$ can be easily explained and a full picture of the mechanism is presented in the Scheme 8.

Besides, in a next study, the same authors evidenced the limitation of the TADF approach with another series of carbazoles Cbz_31-Cbz_34 (See Fig. 24) [136]. If these four dyes have previously been reported as TADF emitters for OLEDs [137], the TADF process doesn't constitute the main deexcitation pathway (10-15\% of the overall deexcitation process) for these compounds so that no modification of the polymerization rates and the monomer conversions could be evidenced between the TADF and the none-TADF photoinitiators. Therefore, it can be concluded that beyond the elongation of the excited state lifetime, the desexcitation from the singlet excited state should constitute the main desexcitation pathway for the molecule in order the photoinitiating ability to be improved.

\subsection{Carbazole-based BOPIDYs}

BODIPYs have been extensively studied as fluorescent probes for bioimaging applications [138-141] but only scarcely for the design of photoinitiators [142-144]. The first carbazole-based BODIPY used as photoinitiator was reported in 2019 (Cbz_35) in the context of a polymerization carried out in the near infrared region (See Fig. 26) [50]. As anticipated, $\mathbf{C b z}_{-} 35$ exhibited a strong absorption centered in the visible region, extending from $400 \mathrm{~nm}$ to $550 \mathrm{~nm}$ with a maximum absorption located at $492 \mathrm{~nm}\left(68080 \mathrm{~L}^{\mathrm{mol}}{ }^{-1} \cdot \mathrm{cm}^{-1}\right)$. Even if the absorption coefficients were extremely low at $785 \mathrm{~nm}\left(170 \mathrm{~L} \cdot \mathrm{mol}^{-1} \cdot \mathrm{cm}^{-1}\right)$ and $940 \mathrm{~nm}\left(100 \mathrm{~L} \cdot \mathrm{mol}^{-1} \cdot \mathrm{cm}^{-1}\right)$, the possibility to initiate the FRP of methacrylates in the NIR region was brilliantly demonstrated. Indeed, photopolymerization at these wavelengths is dominated by cyanines [145-150] but these compounds are expensive so that alternatives are actively researched. While polymerizing a resin composed of a mixture of three monomers (33.3 wt $\%$ of (hydroxypropyl)methacrylate (HPMA), $33.3 \mathrm{wt} \%$ of 1,4-butanediol dimethacrylate (1,4-BDMA) and $33.3 \mathrm{wt} \%$ of a urethane dimethacrylate monomer (UDMA), final monomer conversions of $92 \%$ upon irradiation at $785 \mathrm{~nm}$ and $60 \%$ upon irradiation at $940 \mathrm{~nm}$ could be obtained with the four component system Cbz_35/(t-Bu) $\mathrm{Ph}_{2} \mathrm{I}^{+} / 4$-dppba/BlocBuilder ${ }^{\circledR} \mathrm{MA}$ (0.1 wt $\%$ / $3 \mathrm{wt} \% / 2 \mathrm{wt} \% / 2 \mathrm{wt} \%)$ where 4-dppba and BlockBuilder ${ }^{\circledR M A}$ stand for 4-(diphenylphosphino)benzoic acid and the acronym for a commercial alkoxyamine respectively. Remarkably, in this study, authors combined two polymerization modes, one being based on a pure photochemical system generating radicals through light activation and a second one being based on a photothermal system based on the conversion of light to heat. Indeed, infrared dyes are well-known to generate heat upon photoexcitation. By combining the two polymerization modes, the heat released by photoexcitation but also by the polymerization of methacrylates was sufficient to decompose BlockBuilder ${ }^{\circledR M A}$ which is a thermal initiator of polymerization, improving the final monomer conversion. Interestingly, when the two polymerization modes were considered separately, no or low monomer conversions were obtained, demonstrating that the combination of these two systems is required to get good monomer conversions.

\subsection{Carbazole-based helicoidal photoinitiators}

The solubility of photoinitiators in the photocurable resins is a major issue as it drastically affects the final monomer conversion. This point is of crucial importance, especially when polyaromatic structures (perylenes, pyrenes, pentacene, etc...) are used as photoinitiators. To address this issue, helicenes were proposed as possible structures. Indeed, helicenes are constituted of ortho-fused aromatic rings, enforcing the structure to adopt an helicoidal shape when several aromatic rings are connected together. As a result of this non-planar geometry, the $\pi-\pi$ staking between molecules is efficiently avoided, addressing the solubility issue. In this work, a series of azahelicenes $\mathrm{Cbz}_{-} 36-\mathrm{Cbz}_{-} 38$ differing by the number of angularly annulated aromatic rings and substituents was proposed (See Fig. 27) [151]. Interestingly, presence of an additional aromatic ring in $\mathbf{C b z}_{-} 36$ enabled to redshift the absorp-

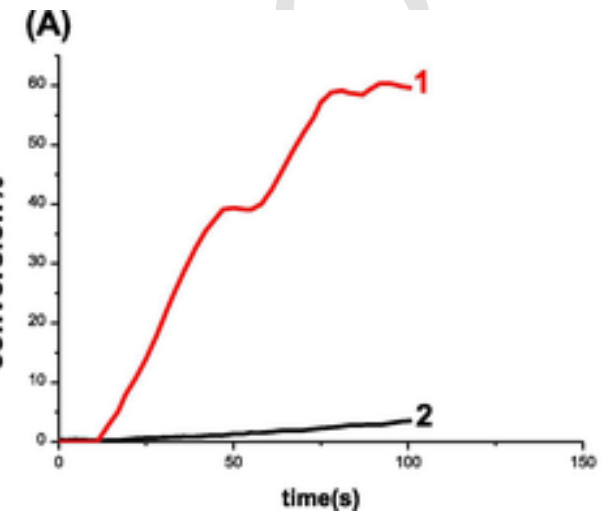

(B)

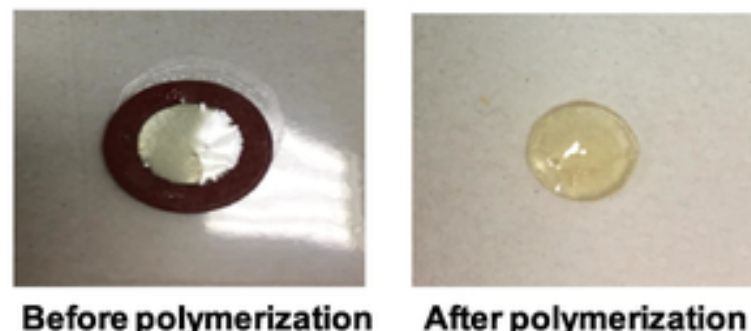

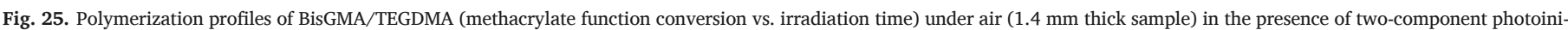

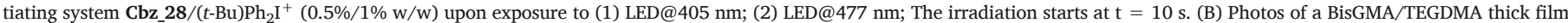

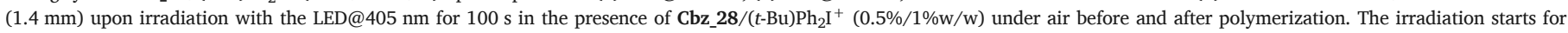
$\mathrm{t}=10 \mathrm{~s}$ Adapted with permission from Al Mousawi et al. [135]. Copyright 2017 American Chemical Society. 


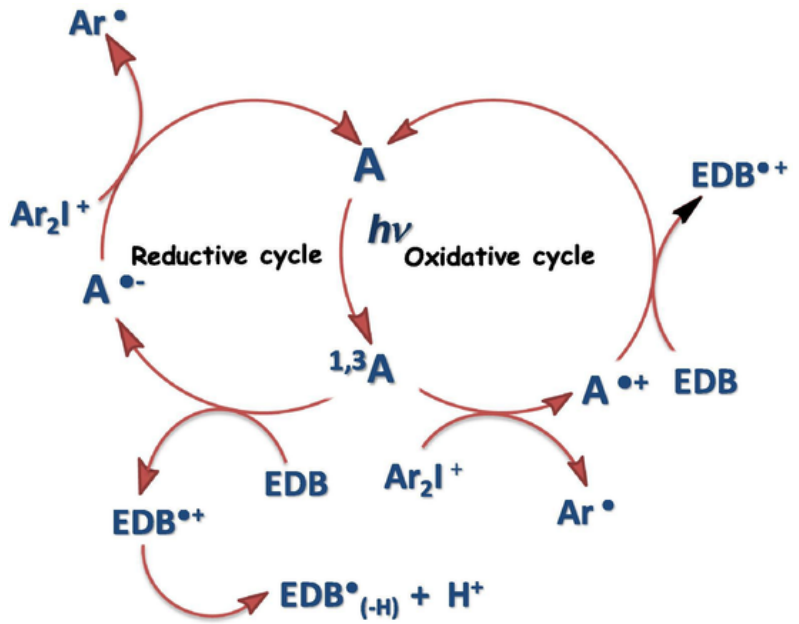

Scheme 8. The two concomitant photoredox catalytic cycles existing in the three compo-

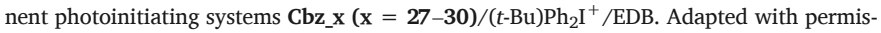
sion from Al Mousawi et al. [135]. Copyright 2017 American Chemical Society.

tion of $50 \mathrm{~nm}$ compared to that of $\mathbf{C b z}_{-} 38$ while increasing the molar extinction coefficient (See Fig. 28). Upon addition of a bromine in Cbz_37, only a slightly redshifted absorption was found compared to that of Cbz_38.

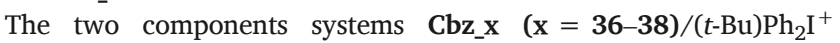
$(0.5 \% / 1 \% \mathrm{w} / \mathrm{w})$ could efficiently initiate the FRPCP of EPOX or the FRP of TMPTA. Especially, higher polymerization rates were found for the polymerization of EPOX and TMPTA, with polymerization processes ended after a few seconds. However, the most interesting finding concerned the photoluminescence of the epoxy films. Indeed, upon photoexcitation of the polymer films for a while and switching the light off, a luminescence persisting over six seconds was observed, tentatively assigned to the presence of photoproducts generated during the polymerization process and/or the presence of unreacted azahelicenes Cbz_36-Cbz_38, despites the non-catalytic character of the two-component system.

\subsection{Carbazole-based ferrocenium}

Ferrocenium salts are attractive structures for the cationic polymerization of epoxides as these compounds are readily available from inexpensive starting materials [152-155]. Notably, these compounds can be prepared in one step by ligand exchange on ferrocene while using a high boiling point apolar solvents and $\mathrm{Al} / \mathrm{AlCl}_{3}$ as the metal catalysts (See Scheme 9). Finally, metathesis with an hexafluorophosphate salt enables to convert the water-soluble ferrocenium salt as a metal salt now soluble in organic solvents. This simple and efficient synthetic method was reported in the early 60 's by Nesmeyanov and co-workers and numerous ferrocenium salts have been prepared using this proce- dure [156,157]. Among ferroceniums, Irgacure 261 i.e. $\left(\eta_{6}\right.$-(1-methylethyl)phenyl) $\eta_{5}$-cyclopentadienyl)iron hexafluorophosphate is a popular photoinitiator of cationic polymerization as this compound is commercially available [158-164]. However, the maximum absorption is centered at $241 \mathrm{~nm}$ and the absorption of Irgacure $261 \mathrm{ex}-$ tends from 200 to $300 \mathrm{~nm}$ so that this ferrocenium salt is a UV-centered photoinitiator. This photoinitiator is thus not for photopolymerization processes carried out in the near UV/visible range.

Numerous works were devoted to redshift the absorption of ferrocenium salts towards the visible range and relevant examples of this hard work were reported in 2006. In fact, the first carbazole-based photoinitiators Cbz_39 and Cbz_40 were published in 2006 and prepared according to the abovementioned procedure (See Fig. 29) [165]. Compared to Irgacure 261 which exhibits a maximum absorption at $241 \mathrm{~nm}$, a redshift as high as $100 \mathrm{~nm}$ was obtained upon replacing the isopropylbenzene ligand of ferrocenium by a carbazole. At $347 \mathrm{~nm}$, introduction of the carbazole moiety resulted in a 30-fold enhancement of the molar extinction coefficients of $\mathbf{C b z}_{-} 39$ and $\mathbf{C b z}_{-} 40$ compared to that of Irgacure 261.

Comparison of the photoinitiating ability of $\mathbf{C b z}_{-} 39$ and $\mathbf{C b z}_{-} \mathbf{4 0}$ with that of Irgacure 261 for wavelength higher than $320 \mathrm{~nm}$ revealed the two carbazole derivatives to outperform Irgacure 261 while simply introducing $2 \%$ of photoinitiators in EPOX. Fast polymerization processes were reported in this work, some polymerization processes being ended after $20 \mathrm{~s}$. However, it has to be noticed that high intensity lamps were used, the intensity ranging between $700 \mathrm{~W}$ for the high-pressure $\mathrm{Hg}$ lamp to $1000 \mathrm{~W}$ for the D-lamp. But the remarkable efficiency of the cationic polymerization is also supported by the proposed mechanism. Notably, a ligand exchange with EPOX resulting from the decoordination of carbazole upon photoexcitation was suggested as a plausible mechanism (See Scheme 10). Such a mechanism has been proposed as soon as 1986 by Riediker and coworkers [166]. Indeed, upon decoordination of the carbazole ligands, a strong Lewis acid is formed, enabling three EPOX units to enter in the coordination sphere of iron and to activate the ring opening of epoxide and the formation of a cation, responsible of the initiation process.

Ten years later, $\mathbf{C b z} 3 \mathbf{3 9}$ was revisited in totally different experimental conditions for the CP of EPOX on the basis of new formulations and the new light sources at disposal [167]. The great achievement of this work compared to the previous one was first the possibility to initiate a polymerization while using low intensity light sources, and second, to develop photoinitiating systems activable under visible light. Notably, authors evidenced that $\mathbf{C b z}_{-} 39$ was efficient to initiate the $\mathrm{CP}$ of EPOX, alone, even upon irradiation of the resins with low light intensity. Thus, final monomer conversions of 57 and 53\% were determined upon irradiation with LEDs at 385 and $405 \mathrm{~nm}$ and by using Cbz_39 without additives. While using the two component $\mathrm{Cbz}_{-} 39 / \mathrm{Ph}_{2} \mathrm{I}^{+}(0.2 \%)$ $2 \%, \mathrm{w} / \mathrm{w}$ ) photoinitiating system, insignificant modifications of the final monomer conversions were found compared to the previous conditions (55 and 57\% respectively determined upon irradiation of the resins
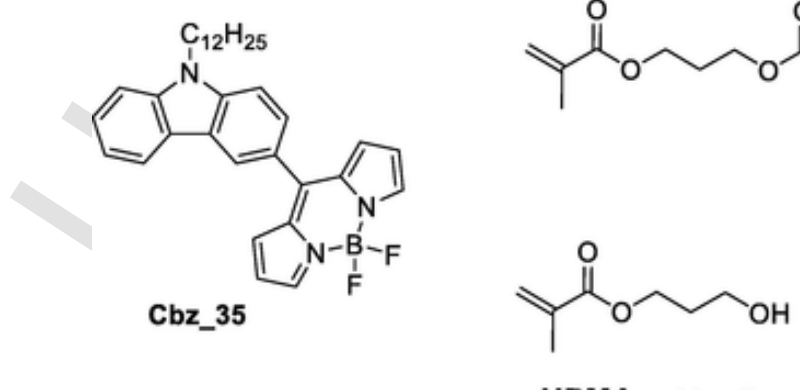

HPMA 33 wt $\%$<smiles>C=C(C)C(=O)OCCCNNC(=O)NNC(=O)OCCCOC(=O)C(=C)C</smiles>

$33 w t \%$

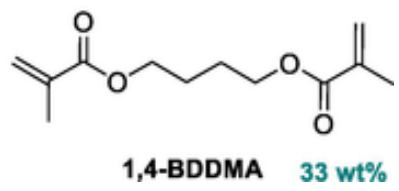

Fig. 26. Chemical structures of Cbz_35 and the different monomers used in the mixture. 


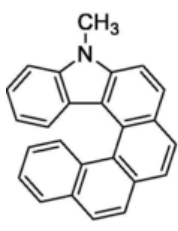

Cbz_36
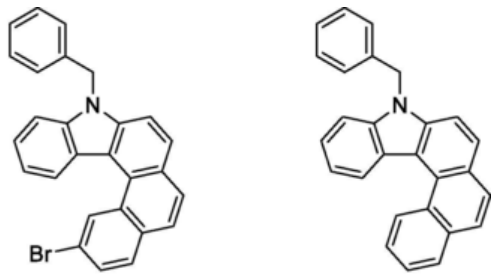

Cbz_38

Fig. 27. Chemical structures of Cbz_36-Cbz_38.

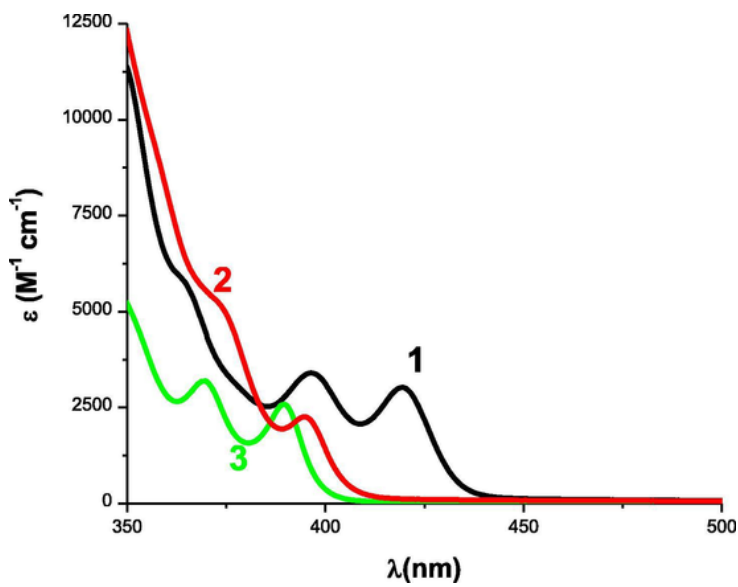

Fig. 28. UV-visible absorption spectra of Cbz_36 (1), Cbz_37 (2) and Cbz_38 (3) in acetonitrile. Reprinted with permission from Al Mousawi et al. [151] Copyright (C) 2017 John Wiley \& Sons, Inc.

with LEDs emitting at $385 \mathrm{~nm}$ and $405 \mathrm{~nm}$ ). However, higher polymerization rates could be determined for the three-component system. While using the $\mathrm{Cbz}_{-} 39 / \mathrm{Ph}_{2} \mathrm{I}^{+} / \mathrm{NVK}(0.2 \% / 2 \% / 3 \%$, w/w) system, the monomer conversion could be increased up to $66 \%$ for an irradiation with a LED@405 nm, resulting from the formation of the highly reactive $\mathrm{Ph}-\mathrm{NVK}^{+}$species. Finally, ferrocenium are well-known cationic photoinitiators but the possibility to initiate the FRP of acrylates was also demonstrated. Indeed, based on the previous reports mentioning the photodissociation of the Fe-cyclopentadiene bond, a cyclopentadienyl radical can be released, initiating the FRP (See Scheme 10). Besides, the different experiments revealed the ability of the cyclopentadienyl radicals to remain limited, the FRP of TMPTA being limited to $8 \%$ for the two-component system $\mathrm{Cbz}_{-}$39/2,4,6-tris(trichloromethyl)-1,3,5-triazine. However, upon addition of EDB, the monomer conversion could be increased up to $44 \%$, demonstrating the validity of the approach.

\subsection{Carbazolium derivatives}

The previous works have clearly demonstrated the carbazole derivatives to efficiently interact with onium salts but also to both accelerate and improve the cationic photopolymerization of epoxides. In this field, NVK is an unavoidable representant of carbazoles. Besides, by quaternization of the amine of carbazole, photoinitiators for FRP can also be obtained as exemplified with Cbz_41 (See Scheme 11) [168]. Chemical structure of $\mathbf{C b z} 4 \mathbf{4 1}$ is directly inspired from the structures of phenacyl onium salts that are highly photosensitive compounds [169]. Notably, phenacyl onium salts are well-known to initiate a homolytic and/or a heterolytic bond cleavage upon irradiation so that radicals and cations can be both generated upon photolysis [170-178]. In the case of Cbz_41, cyclic voltammetric and photobleaching experiments revealed the carbazole moieties to give rise to an extension of conjugation, attributed to the dimerization of carbazole radical cations. Indeed, the radical cations formed during the homolytic bond cleavage can further interact, as shown in the Scheme 10. To investigate the applicability of $\mathbf{C b z}_{-} \mathbf{4 1}$, the photopolymerization of various monomers such as methyl methacrylate, methacrylic acid, styrene and NVK was investigated. Polymerization of all monomers was successfully achieved, providing polymers of high monomer conversions. Consequently, photolysis of the Cbz_41 salt by homolytic cleavage was clearly demonstrated, the polymerization of the previous monomers being only possible by the photogeneration of free radicals. Conversely, all attempts of cationic polymerization failed due to the improbability of an electron transfer to yield cationic species and the tendency of photofragments to dimerize under irradiation.

\subsection{Carbazoles used as monomers and photoinitiators}

At present, all the carbazole derivatives reported in this review have been used as photoinitiators and not as monomers for their own photopolymerizations. This original strategy was reported in 2018 with $N$-ethylcarbazole Cbz_42 [179]. As specificity, light-induced step-growth polymerization doesn't require any photoinitiator to proceed and the initiation, propagation and termination steps cannot be distinguished [180]. Contrarily to the previous works where non-conjugated polymers are obtained, photopolymerization of $\mathbf{C b z}_{-} \mathbf{4 2}$ could furnish a poly(carbazole). Poly(carbazoles) are extensively studied in Organic Electronics as these polymers are semi-conductors exhibiting an excellent film-forming ability which is of crucial importance to avoid shortcuts in devices $[75,181]$. In this field, poly( $N$-vinylcarbazole) (PVK) is one of the most representative polymers. PVK is notably commonly used as hole-transport materials for the design of solution-processed organic light-emitting diodes (OLEDs) due to its remarkable morphological stability and its good solubility in most of the common organic solvents. Therefore, devices can be prepared by wet-process while using PVK [76,182-184]. Parallel to PVK derivatives in which carbazole units are connected by mean of a none-conjugated main chain, carbazoles can also be connected by forming carbon-carbon bonds between aromatic rings, generating $\pi$-conjugated polymers. The most popular strategies are notably oxidative polymerization [185], electropolymerization [186] and metal-catalyzed cross-coupling reactions $[187,188]$. In 2018, Yagci and coworkers proposed an original synthesis based on an electron-transfer between carbazole and an iodonium salt. When mixed in solution, appearance of a broad band between 500 and $750 \mathrm{~nm}$ in the UV-visible absorption spectrum of Cbz_42 confirmed the formation of a doped conjugated polymer upon irradiation. Additionally, the photopolymerized polymer which is obtained as a doped polymer could be dedoped by treatment with hydrazinium hydroxide in methanol. Authors also evidenced the step-growth polymer-

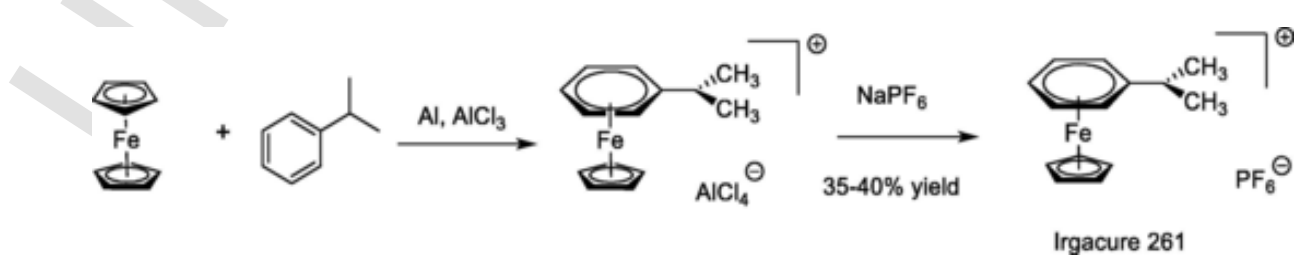

Scheme 9. Synthetic route to Irgacure 261. 


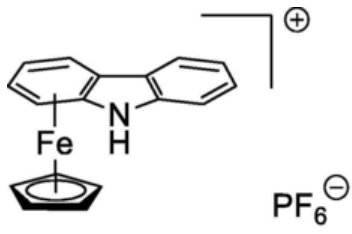

Cbz_39

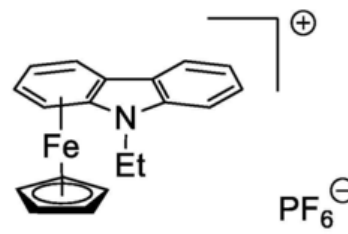

Cbz_40
Fig. 29. Chemical structures for $\mathrm{Cbz}_{-} 39$ and $\mathrm{Cbz}_{-} 40$.

ization of poly( $N$-ethylcarbazole) to result from successive cycles of photoinduced electron transfer and coupling of radical cations, as shown in the Scheme 12. In fact, this mechanism is similar to that previously reported for the photopolymerization of polythiophenes [189-191]. Examination of the polymer films by atomic Force Spectroscopy (AFM) revealed the morphology of the doped and dedoped polymer layers to be drastically different. Notably, an increased roughness for the dedoped polymer layers was observed, assigned to a strong $\pi-\pi$ stacking between carbazole as a result of $\mathrm{PF}_{6}{ }^{-}$anions removal (See Fig. 30).

\section{Conclusions -perspectives}

During the last decades, a wide range of carbazole derivatives have been proposed as photoinitiators of polymerization. The advantages of carbazole-based photoinitiators compared to other newly developed photoinitiators are numerous. Among the most interesting features, their low cost, low toxicity, high reactivity, good thermal and photochemical stability, good solubility in monomers, ease to handle (powders), high absorptions in the near visible/visible range making these photoinitiators ideal candidates for 3D-printing applications, possibility to prepare organometallic structures by using carbazole as a ligand can be cited as appealing characteristics. Contrarily to numerous photoinitiators that have fallen by the wayside due to a difficult synthetic access, chemistry of carbazole is relatively simple and most of the carbazole derivatives reported in this review have been obtained in high yields by simple purifications processes (precipitation, recrystallisation). From this point of view, carbazoles are promising candidates for future industrial transfer and materials applications. But the different families of carbazole-based photoinitiators listed in this review are not equivalent as far as their photoreactivities is concerned.

Among the series of forty carbazole derivatives reported in the literature, the most important family is undoubtedly based on nitrogen-con-

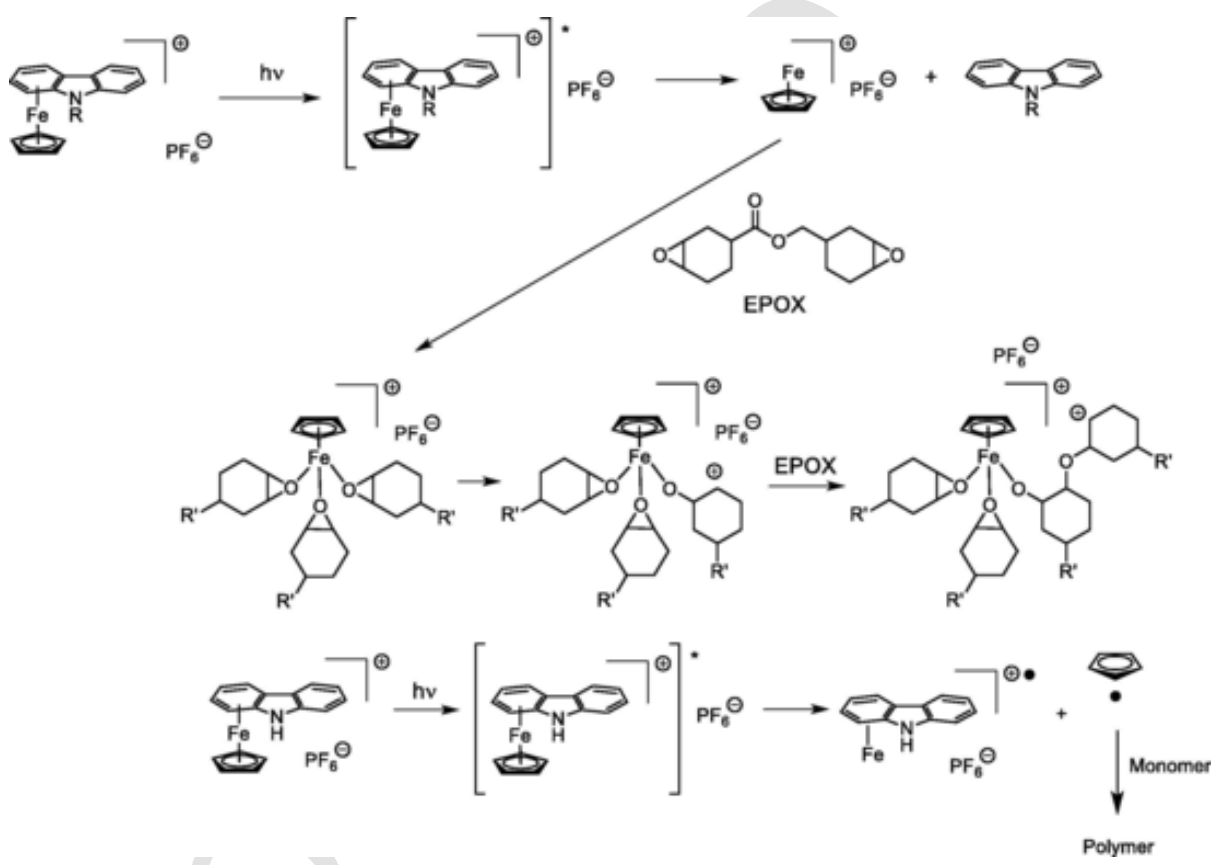

Scheme 10. Mechanism suggested to support the photoinitiating ability of carbazole-based ferrocenium salt.

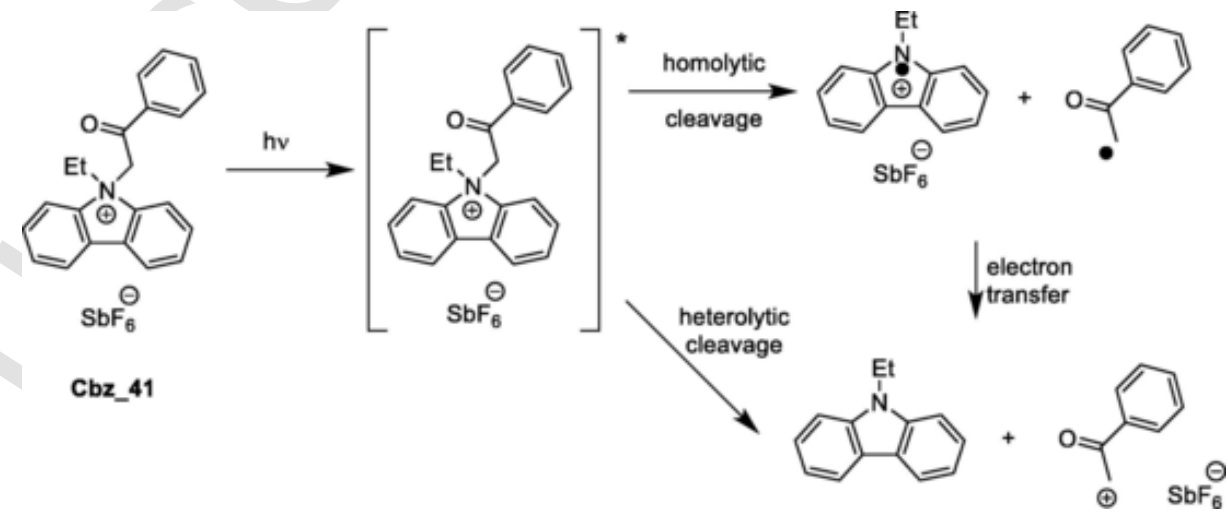

Scheme 11. The different photoproducts obtained during photolysis of phenacyl onium salts. 
<smiles>CCn1c2ccccc2c2ccccc21</smiles>

Cbz_42<smiles>CCc1ccc2c(c1)c1ccccc1n2CC</smiles>

L

$$
\text { J }
$$

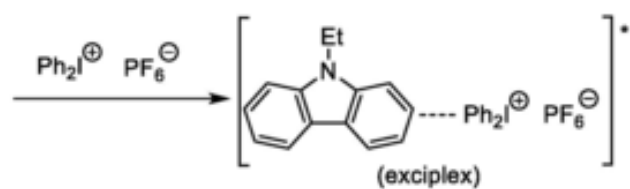

(exciplex)<smiles>[3H][3H]</smiles>
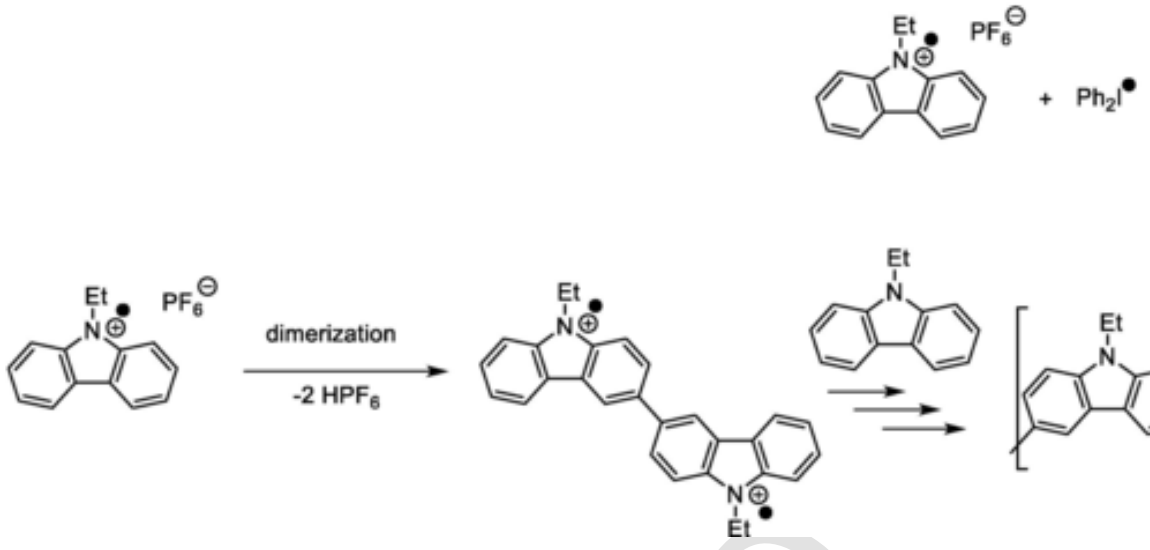

Scheme 12. Step-growth photopolymerization mechanism of poly(N-ethylcarbazole).

a)

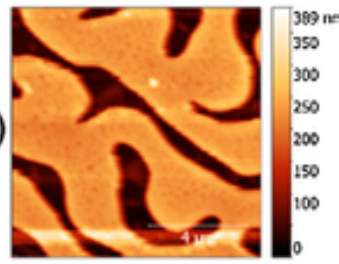

TOPOGRAPHY

b)

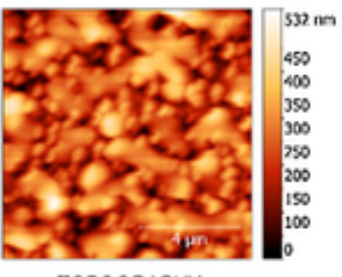

TOPOGRAPHY

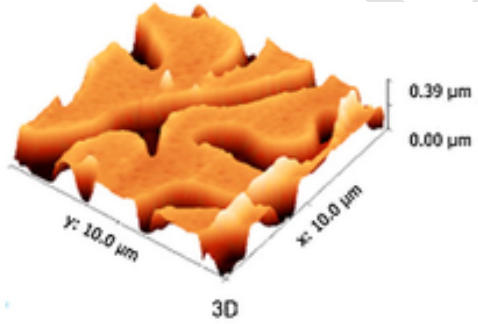

30

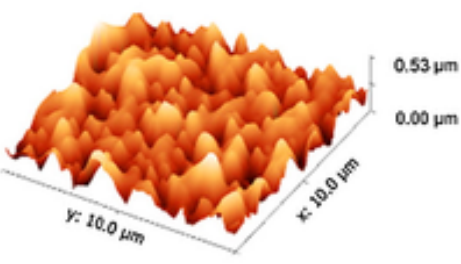

30

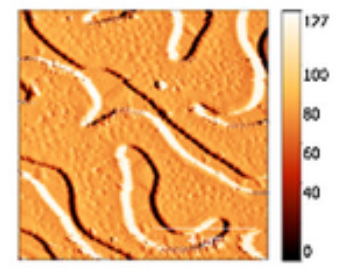

PHASE

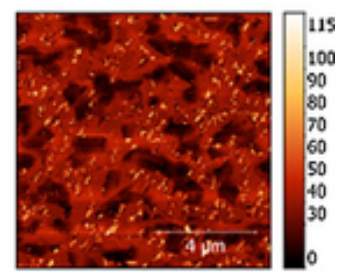

PHASE

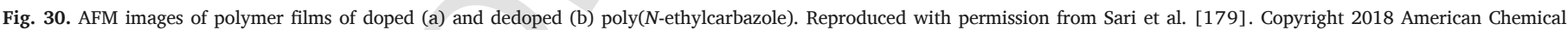
Society.

taining polyaromatic hydrocarbons. Using this strategy, compounds with absorption in the near-UV/visible region have been developed and the different setups previously used for an initiation of the polymerization process in the UV range can be still used with these photoinitiators. Besides, with regards to the development of the new, compact, low-consuming and cheap irradiation setups, a new generation of photoinitiators totally disconnected from the UV photoinitiators have been proposed, as exemplified with the push-pull dyes, Bodipys or TADF photoinitiators. With these different structures, absorption spectra strongly centered in the visible range are obtained. The last family of photoinitiators i.e. the TADF photoinitiators whose TADF property have only been discovered by Chihaya Adachi in 2012 clearly deserves to be further investigated due to the significant enhancement of the excited state lifetime that could be obtained by chemical engineering. Parallel to the neutral photoinitiators, two families of cationic photoinitiators, namely ferrocenium and carbazolium have respectively been designed for the $\mathrm{CP}$ of epoxides or the FRP of acrylates. Concerning carbazoliums, the performances reported at present are far behind that of benchmark photoinitiators so that an extensive work needs to be carried out to improve the photoinitiating ability of these derivatives. Considering that carbazole is a versatile building block, further developments of photoinitiators will consist in elaborating near-infrared dyes, the light penetration into the photocurable resins being the main parameter governing the reactivity of photoinitiators and thus the polymerization speed.

As other promising future application for carbazole-based photoinitiators is the preparation of materials. Indeed, carbazoles, by their strong absorption in the near-visible/visible range, are perfect candidates for photopolymerization at $405 \mathrm{~nm}$, and thus constitutes ideal candidates for 3D-printing applications. The recent works done by Yagci and coworkers on the step-growth polymerization of poly( $N$-ethylcarbazole) also paves the way towards applications in Organic Elec- 
tronics. Future developments of carbazole-based photoinitiators in this vast research field is directly related to the ability to design $\pi$-conjugated polymers, opening the way towards new and unexpected applications.

\section{Declaration of Competing Interest}

The authors declare that they have no known competing financial interests or personal relationships that could have appeared to influence the work reported in this paper.

\section{Acknowledgment}

The author thanks Aix Marseille University and the Centre National de la Recherche Scientifique (CNRS) for financial support.

\section{References}

[1] J.V. Crivello, E. Reichmanis, Photopolymer materials and processes for advanced technologies, Chem. Mater. 26 (2014) 533-548.

[2] C. Dietlin, S. Schweizer, P. Xiao, J. Zhang, F. Morlet-Savary, B. Graff, J.-P. Fouassier, J. Lalevée, Photopolymerization upon LEDs: new photoinitiating systems and strategies, Polym. Chem. 6 (2015) 3895-3912.

[3] P. Xiao, J. Zhang, F. Dumur, M.-A. Tehfe, F. Morlet-Savary, B. Graff, D. Gigmes, J.-P. Fouassier, J. Lalevée, Photoinitiating systems: recent progress in visible light induced cationic and radical photopolymerization reactions under soft conditions, Prog. Polym. Sci. 41 (2015) 32-66.

[4] P. Garra, C. Dietlin, F. Morlet-Savary, F. Dumur, D. Gigmes, J.-P. Fouassier, J. Lalevée, Photopolymerization processes of thick films and in shadow areas: a review for the access to composites, Polym. Chem. 8 (2017) 7088-7101.

[5] S. Shanmugam, J. Xu, C. Boyer, Photocontrolled living polymerization systems with reversible deactivations through electron and energy transfer, Macromol. Rapid Commun. 38 (2017) 1700143.

[6] Z. Zhang, N. Corrigan, A. Bagheri, J. Jin, C. Boyer, A versatile 3d and 4d printing system through photocontrolled raft polymerization, Angew. Chem. Int. Ed. 58 (2019) 17954-17963.

[7] B.L. Buss, G.M. Miyake, Photoinduced controlled radical polymerizations performed in flow: methods, products, and opportunities, Chem. Mater. 30 (2018) 3931-3942.

[8] C. Mendes-Felipe, J. Oliveira, I. Etxebarria, J.L. Vilas-Vilela, S. Lanceros-Mendez, State-of-the-art and future challenges of uv curable polymer-based smart materials for printing technologies, Adv. Mater. Technol. 4 (2019) 1800618.

[9] A. Bagheri, J. Jin, Photopolymerization in 3D Printing, ACS Appl. Polym. Mater. 1 (2019) 593-611.

[10] C. Noè, S. Malburet, A. Bouvet-Marchand, A. Graillot, C. Loubat, M. Sangermano, Cationic photopolymerization of bio-renewable epoxidized monomers, Prog. Org. Coat. 133 (2019) 131-138.

[11] J. Shao, Y. Huang, Q. Fan, Visible light initiating systems for photopolymerization: status, development and challenges, Polym. Chem. 5 (2014) 4195-4210.

[12] H.K. Park, M. Shin, B. Kim, J.W. Park, H. Lee, A visible light-curable yet visible wavelength-transparent resin for stereolithography 3D printing, NPG Asia Mater. 10 (2018) 82-89.

[13] F. Yoshino, A. Yoshida, Effects of blue-light irradiation during dental treatment, Jpn Dent. Sci. Rev. 54 (2018) 160-168.

[14] M.L. Gomez, C.M. Previtali, H.A. Montejano, Two- and three-component visible light photoinitiating systems for radical polymerization based on onium salts: an overview of mechanistic and laser flash photolysis studies, Int. J. Photoenergy 260728 (2012)

[15] M. Mitterbauer, P. Knaack, S. Naumov, M. Markovic, A. Ovsianikov, N. Moszner, R. Liska, Acylstannanes: Cleavable and highly reactive photoinitiators for radical photopolymerization at wavelengths above $500 \mathrm{~nm}$ with excellent photobleaching behavior, Angew. Chem. Int. Ed. 57 (2018) 12146-12150.

[16] J. Radebner, A. Eibel, M. Leypold, N. Jungwirth, T. Pickl, A. Torvisco, R. Fischer, U.K. Fischer, N. Moszner, G. Gescheidt, H. Stueger, M. Haas, Tetraacylstannanes as long-wavelength visible-light photoinitiators with intriguing low toxicity, Chem. Eur. J. 24 (2018) 8281-8285.

[17] A. Eibel, D.E. Fast, G. Gescheidt, Choosing the ideal photoinitiator for free radical photopolymerizations: predictions based on simulations using established data, Polym. Chem. 9 (2018) 5107-5115.

[18] A. Eibel, J. Radebner, M. Haas, D.E. Fast, H. Freißmuth, E. Stadler, P. Faschauner, A. Torvisco, I. Lamparth, N. Moszner, H. Stueger, G. Gescheidt, Polym. Chem. 9 (2018) 38-47.

[19] M. Bouzrati-Zerelli, N. Zivic, F. Dumur, D. Gigmes, B. Graff, J.-P. Fouassier, J. Lalevée, New violet to yellow light sensitive diketopyrrolo-pyrrole photoinitiators: high performance systems with unusual bleaching properties and solubility in water, Polym. Chem. 8 (2017) 2028-2040.

[20] M.-A. Tehfe, F. Dumur, S. Telitel, D. Gigmes, E. Contal, D. Bertin, F. Morlet-Savary, B. Graff, J.-P. Fouassier, J. Lalevée, Zinc-based metal complexes as new photocatalysts in polymerization initiating systems, Eur. Polym. J. 49 (2013) 1040-1049.

[21] J. Li, Y. Hao, M. Zhong, L. Tang, J. Nie, X. Zhu, Synthesis of furan derivative as LED light photoinitiator: one-pot, low usage, photobleaching for light color 3D printing, Dyes Pigm. 165 (2019) 467-473.

[22] E.A. Kamoun, A. Winkel, M. Eisenburger, H. Menzel, Carboxylated camphorquinone as visible-light photoinitiator for biomedical application: synthesis, characterization, and application, Arab. J. Chem. 9 (2016) 745-754.

[23] A.H. Bonardi, F. Dumur, T.M. Grant, G. Noirbent, D. Gigmes, B.H. Lessard, J.-P. Fouassier, J. Lalevée, High performance near infrared (NIR) photoinitiating systems operating under low light intensity and in presence of oxygen, Macromolecules 51 (2018) 1314-1324.

[24] M.-A. Tehfe, F. Dumur, P. Xiao, M. Delgove, B. Graff, J.-P. Fouassier, D. Gigmes, J. Lalevée, Chalcone derivatives as highly versatile photoinitiators for radical, cationic, thiol-ene and IPN polymerization reactions upon visible lights, Polym. Chem. 5 (2014) 382-390.

[25] M.-A. Tehfe, F. Dumur, P. Xiao, B. Graff, F. Morlet-Savary, J.-P. Fouassier, D. Gigmes, J. Lalevée, New chromone based photoinitiators for polymerization reactions upon visible lights, Polym. Chem. 4 (2013) 4234-4244.

[26] A. Al Mousawi, P. Garra, M. Schmitt, J. Toufaily, T. Hamieh, B. Graff, J.-P. Fouassier, F. Dumur, J. Lalevée, 3-Hydroxyflavone and N-phenyl-glycine in high performance photo-initiating systems for 3D printing and photocomposites synthesis, Macromolecules 51 (2018) 4633-4641.

[27] A. Al Mousawi, P. Garra, F. Dumur, B. Graff, J.-P. Fouassier, J. Lalevée, Flavones as natural photoinitiators for light mediated free radical polymerization via light emitting diodes, J. Polym. Sci. A Polym. Chem. (2019), doi:10.1002/pola.29545.

[28] P. Xiao, F. Dumur, M. Frigoli, B. Graff, F. Morlet-Savary, G. Wantz, H. Bock, J.-P. Fouassier, D. Gigmes, J. Lalevée, Perylene derivatives as photoinitiators in blue light sensitive cationic or radical curable films and panchromatic thiol-ene polymerizable films, Eur. Polym. J. 53 (2014) 215-222.

[29] M.-A. Tehfe, F. Dumur, B. Graff, D. Gigmes, J.-P. Fouassier, J. Lalevée, Green light induced cationic ring opening polymerization reactions: perylene-3,4:9,10-bis(dicarboximide) as efficient photosensitizers, Macromol. Chem. Phys. 214 (2013) 1052-1060.

[30] P. Xiao, F. Dumur, B. Graff, D. Gigmes, J.-P. Fouassier, J. Lalevée, Red-light-induced cationic photopolymerization: perylene derivatives as efficient photoinitiators, Macromol. Rapid Commun. 34 (2013) 1452-1458.

[31] J. Zhang, N. Zivic, F. Dumur, C. Guo, Y. Li, P. Xiao, B. Graff, D. Gigmes, J.-P. Fouassier, J. Lalevée, Panchromatic photoinitiators for radical, cationic and thiol-ene polymerization reactions: a search in the diketopyrrolopyrrole or indigo dye series, Mater. Today Commun. 4 (2015) 101-108.

[32] P. Xiao, W. Hong, Y. Li, F. Dumur, B. Graff, J.-P. Fouassier, D. Gigmes, J. Lalevée, Diketopyrrolopyrrole dyes: structure/reactivity/efficiency relationship in photoinitiating systems upon visible lights, Polymer 55 (2014) 746-751.

[33] P. Xiao, W. Hong, Y. Li, F. Dumur, B. Graff, J.-P. Fouassier, D. Gigmes, J. Lalevée, Green light sensitive diketopyrrolopyrrole derivatives used in versatile photoinitiating systems for photopolymerizations, Polym. Chem. 5 (2014) 2293-2300.

[34] M.-A. Tehfe, F. Dumur, E. Contal, B. Graff, D. Gigmes, J.-P. Fouassier, J. Lalevée, Novel highly efficient organophotocatalysts: truxene-acridine-1,8-diones as photoinitiators of polymerization, Macromol. Chem. Phys. 214 (2013) 2189-2201.

[35] P. Xiao, F. Dumur, M.-A. Tehfe, B. Graff, D. Gigmes, J.-P. Fouassier, J. Lalevée Acridinediones: effect of substituents on their photoinitiating abilities in radical and cationic photopolymerization, Macromol. Chem. Phys. 214 (2013) 2276-2282.

[36] P. Xiao, F. Dumur, M.-A. Tehfe, B. Graff, D. Gigmes, J.-P. Fouassier, J. Lalevée, Difunctional acridinediones as photoinitiators of polymerization under UV and visible lights: structural effects, Polymer 54 (2013) 3458-3466.

[37] A.-H. Bonardi, S. Zahouily, C. Dietlin, B. Graff, F. Morlet-Savary, M. Ibrahim-Ouali, D. Gigmes, N. Hoffmann, F. Dumur, J. Lalevée, New 1,8-naphthalimide derivatives as photoinitiators for free radical polymerization upon visible light, Catalysts 9 (2019) 637.

[38] J. Zhang, N. Zivic, F. Dumur, P. Xiao, B. Graff, J.-P. Fouassier, D. Gigmes, J. Lalevée, Naphthalimide-tertiary amine derivatives as blue-light-sensitive photoinitiators, ChemPhotoChem 2 (2018) 481-489.

[39] P. Xiao, F. Dumur, J. Zhang, B. Graff, D. Gigmes, J.-P. Fouassier, J. Lalevée, Naphthalimide derivatives: substituent effects on the photoinitiating ability in polymerizations under near UV, purple, white and blue LEDs (385 nm, $395 \mathrm{~nm}, 405 \mathrm{~nm}$, $455 \mathrm{~nm}$ or $470 \mathrm{~nm}$ ), Macromol. Chem. Phys. 216 (2015) 1782-1790.

[40] P. Xiao, F. Dumur, J. Zhang, B. Graff, D. Gigmes, J.-P. Fouassier, J. Lalevée, Naphthalimide-phthalimide derivative based photoinitiating systems for polymerization reactions under blue lights, J. Polym. Sci. A Polym. Chem. 53 (2015) 665-674.

[41] J. Zhang, N. Zivic, F. Dumur, P. Xiao, B. Graff, D. Gigmes, J.-P. Fouassier, J. Lalevée, A benzophenone-naphthalimide derivative as versatile photoinitiator for near UV and visible lights, J. Polym. Sci. A Polym. Chem. 53 (2015) 445-451.

[42] J. Zhang, N. Zivic, F. Dumur, P. Xiao, B. Graff, J.-P. Fouassier, D. Gigmes, J. Lalevée, $N$-[2-(dimethylamino)ethyl]-1,8-naphthalimide derivatives as photoinitiators under LEDs, Polym. Chem. 9 (2018) 994-1003.

[43] N. Zivic, J. Zhang, D. Bardelang, F. Dumur, P. Xiao, T. Jet, D.-L. Versace, C. Di etlin, F. Morlet-Savary, B. Graff, J.-P. Fouassier, D. Gigmes, J. Lalevée, Novel naphthalimide-amine based photoinitiators operating under violet and blue LEDs and usable for various polymerization reactions and synthesis of hydrogels, Polym. Chem. 7 (2016) 418-429.

[44] J. Zhang, F. Dumur, P. Xiao, B. Graff, D. Bardelang, D. Gigmes, J.-P. Fouassier, J. Lalevée, Structure design of naphthalimide derivatives: towards versatile photo- 
initiators for near UV/Visible LEDs, 3D printing and water soluble photoinitiating systems, Macromolecules 48 (2015) 2054-2063.

[45] J. Zhang, N. Zivic, F. Dumur, P. Xiao, B. Graff, J.-P. Fouassier, D. Gigmes, J. Lalevée, UV-violet-blue LED induced polymerizations: specific photoinitiating systems at 365, 385, 395 and 405 nm, Polymer 55 (2014) 6641-6648.

[46] P. Xiao, F. Dumur, B. Graff, D. Gigmes, J.-P. Fouassier, J. Lalevée, Blue light sensitive dyes for various photopolymerization reactions: naphthalimide and naphthalic anhydride derivatives, Macromolecules 47 (2014) 601-608.

[47] P. Xiao, F. Dumur, M. Frigoli, M.-A. Tehfe, B. Graff, J.-P. Fouassier, D. Gigmes, J. Lalevée, Naphthalimide based methacrylated photoinitiators in radical and cationic photopolymerization under visible light, Polym. Chem. 4 (2013) 5440-5448.

[48] H. Mokbel, J. Toufaily, T. Hamieh, F. Dumur, D. Campolo, D. Gigmes, J.-P. Fouassier, J. Ortyl, J. Lalevee, Specific cationic photoinitiators for Near UV and visible LEDs: iodonium vs. ferrocenium structures, J. Appl. Polym. Sci. 132 (2015) 42759.

49] N. Zivic, M. Bouzrati-Zerrelli, S. Villotte, F. Morlet-Savary, C. Dietlin, F. Dumur, D. Gigmes, J.-P. Fouassier, J. Lalevée, A novel naphthalimide scaffold based iodonium salt as a one-component photoacid/photoinitiator for cationic and radical polymerization under LED exposure, Polym. Chem. 7 (2016) 5873-5879.

[50] A. Bonardi, F. Bonardi, G. Noirbent, F. Dumur, C. Dietlin, D. Gigmes, J.-P. Fouassier, J. Lalevée, Different NIR dye scaffolds for polymerization reactions under NIR light, Polym. Chem. 10 (2019) 6505-6514.

[51] A. Al Mousawi, C. Poriel, F. Dumur, J. Toufaily, T. Hamieh, J.-P. Fouassier, J. Lalevée, Zinc-tetraphenylporphyrin as high performance visible-light photoinitiator of cationic photosensitive resins for LED projector 3D printing applications, Macromolecules 50 (2017) 746-753.

[52] S. Telitel, F. Dumur, T. Faury, B. Graff, M.-A. Tehfe, D. Gigmes, J.-P. Fouassier, J. Lalevée, New core-pyrene $\pi$-structure organophotocatalysts usable as highly efficient photoinitiators, Beilstein J. Org. Chem. 9 (2013) 877-890.

[53] S. Telitel, F. Dumur, D. Gigmes, B. Graff, J.-P. Fouassier, J. Lalevée, New functionalized aromatic ketones as photoinitiating systems for near visible and visible light induced polymerizations, Polymer 54 (2013) 2857-2864.

[54] M.-A. Tehfe, F. Dumur, E. Contal, B. Graff, F. Morlet-Savary, D. Gigmes, J.-P. Fouassier, J. Lalevée, New insights in radical and cationic polymerizations upon visible light exposure: role of novel photoinitiator systems based on the pyrene chromophore, Polym. Chem. 4 (2013) 1625-1634.

[55] M.-A. Tehfe, F. Dumur, B. Graff, F. Morlet-Savary, J.-P. Fouassier, D. Gigmes, J. Lalevée, Trifunctional photoinitiators based on a triazine skeleton for visible light sources and UV LED induced polymerizations, Macromolecules 45 (2012) 8639-8647.

[56] M.-A. Tehfe, F. Dumur, B. Graff, F. Morlet-Savary, D. Gigmes, J.-P. Fouassier, J. Lalevée, Design of new Type I \& Type II photoinitiators possessing highly coupled pyrene-ketone moieties, Polym. Chem. 4 (2013) 2313-2324.

[57] P. Xiao, F. Dumur, B. Graff, D. Gigmes, J.-P. Fouassier, J. Lalevée, Variations on the benzophenone skeleton: novel high performance blue light sensitive photoinitiating systems, Macromolecules 46 (2013) 7661-7667.

[58] J. Zhang, M. Frigoli, F. Dumur, P. Xiao, L. Ronchi, B. Graff, F. Morlet-Savary, J.-P. Fouassier, D. Gigmes, J. Lalevée, Design of novel photoinitiators for radical and cationic photopolymeri-zations under Near UV and Visible LEDs (385, 395 and $405 \mathrm{~nm}$ ), Macromolecules 47 (2014) 2811-2819.

[59] A. Allushi, C. Kutahya, C. Aydogan, J. Kreutzer, G. Yilmaz, Y. Yagci, Conventiona Type II photoinitiators as activators for photoinduced metal-free atom transfer radical polymerization, Polym. Chem. 8 (2017) 1972-1977.

[60] P. Xiao, M. Frigoli, F. Dumur, B. Graff, D. Gigmes, J.-P. Fouassier, J. Lalevée, Julolidine or fluorenone based push-pull dyes for polymerization upon soft polychromatic visible light or green light, Macromolecules 47 (2014) 106-112.

[61] H. Mokbel, F. Dumur, S. Telitel, L. Vidal, P. Xiao, D.-L. Versace, M.-A. Tehfe, F. Morlet-Savary, B. Graff, J.-P. Fouassier, D. Gigmes, J. Toufaily, T. Hamieh, J. Lalevée, Photoinitiating systems of polymerization and in-situ incorporation of metal nanoparticles in polymer matrixes upon visible lights: push-pull malonate and malonitrile based dyes, Polym. Chem. 4 (2013) 5679-5687.

[62] M.-A. Tehfe, F. Dumur, B. Graff, F. Morlet-Savary, J.-P. Fouassier, D. Gigmes, J. Lalevée, New push-pull dyes derived from michler's ketone for polymerization reactions upon visible lights, Macromolecules 46 (10) (2013) 3761-3770, doi:10.1021/ma400766z.

[63] M.-A. Tehfe, F. Dumur, B. Graff, D. Gigmes, J.-P. Fouassier, J. Lalevée, Blue-to-red light sensitive push-pull structured photoinitiators: indanedione derivatives for radical and cationic photopolymerization reactions, Macromolecules 46 (2013) 3332-3341.

[64] H. Mokbel, F. Dumur, C.R. Mayer, F. Morlet-Savary, B. Graff, D. Gigmes, J. Toufaily, T. Hamieh, J.-P. Fouassier, J. Lalevée, End capped polyenic structures as visible light sensitive photoinitiators for polymerization of vinylethers, Dyes Pigm. 105 (2014) 121-129.

[65] P. Garra, D. Brunel, G. Noirbent, B. Graff, F. Morlet-Savary, C. Dietlin, V.F. Sidorkin, F. Dumur, D. Duché, D. Gigmes, J.-P. Fouassier, J. Lalevée, Ferrocene-based (photo)redox polymerization under long wavelengths, Polym. Chem. 10 (2019) 1431-1441.

[66] M. Abdallah, T.-T. Bui, F. Goubard, D. Theodosopoulou, F. Dumur, A. Hijazi, J.-P. Fouassier, J. Lalevée, Phenothiazine derivatives as photoredox catalysts for cationic and radical photosensitive resins for 3D printing technology and photocomposites synthesis, Polym. Chem. 10 (2019) 6145-6156.

[67] S. Telitel, F. Dumur, T. Kavalli, B. Graff, F. Morlet-Savary, D. Gigmes, J.-P. Fouassier, J. Lalevée, The 1,3-bis(dicyanomethylidene)-indane skeleton as a (photo) initiator in thermal ring opening polymerization at RT and radical or cationic photopolymerization, RSC Adv. 4 (2014) 15930-15936.

[68] H. Mokbel, F. Dumur, B. Graff, C.R. Mayer, D. Gigmes, J. Toufaily, T. Hamieh, J.-P. Fouassier, J. Lalevée, Michler's ketone as an interesting scaffold for the design of high performance dyes in photoinitiating systems upon visible lights, Macromol. Chem. Phys. 215 (2014) 783-790.

[69] P. Xiao, F. Dumur, B. Graff, F. Morlet-Savary, L. Vidal, D. Gigmes, J.-P. Fouassier J. Lalevée, Structural effects in the indanedione skeleton for the design of low intensity 300-500 nm light sensitive initiators, Macromolecules 47 (2014) 26-34.

[70] M. Abdallah, A. Hijazi, B. Graff, J.-P. Fouassier, G. Rodeghiero, A. Gualandi, F. Dumur, P.G. Cozzi, J. Lalevée, Coumarin derivatives as high performance visible light photoinitiators/ photoredox catalysts for photosensitive resins for 3D printing technology, photopolymerization in water and photocomposites synthesis, Polym. Chem. 10 (2019) 872-884.

[71] P. Xiao, F. Dumur, D. Thirion, S. Fagour, S. Vacher, X. Sallenave, F. Morlet-Savary, B. Graff, J.-P. Fouassier, D. Gigmes, J. Lalevée, Multicolor photoinitiators for radical and cationic polymerization: mono vs. poly functional thiophene derivatives, Macromolecules 46 (2013) 6786-6793.

[72] M.-A. Tehfe, A. Zein-Fakih, J. Lalevée, F. Dumur, D. Gigmes, B. Graff, F. Morlet-Savary, T. Hamieh, J.-P. Fouassier, New pyridinium salts as versatile compounds for dye sensitized photo-polymerization, Eur. Polym. J. 49 (2013) 567-574

[73] J. Zhang, J. Lalevée, J. Zhao, B. Graff, M.H. Stenzel, P. Xiao, Dihydroxyanthraquinone derivatives: natural dyes as blue-light-sensitive versatile photoinitiators of photopolymerization, Polym. Chem. 7 (2016) 7316-7324.

[74] F. Dumur, D. Gigmes, J.-P. Fouassier, J. Lalevée, Organic Electronics: an El Dorado in the quest of new photoCatalysts as photoinitiators of polymerization, Acc. Chem. Res. 49 (2016) 1980-1989.

[75] F. Dumur, Carbazole-based polymers as hosts for solution-processed organic light-emitting diodes: simplicity, efficacy, Org. Electron. 25 (2015) 345-361.

[76] F. Dumur, L. Beouch, S. Peralta, G. Wantz, F. Goubard, D. Gigmes, Solution-processed blue phosphorescent OLEDs with carbazole-based polymeric host materials, Org. Electron. 25 (2015) 21-30.

[77] G. Puckyte, B. Schmaltz, A. Tomkeviciene, M. Degbia, J.V. Grazulevicius, H. Melhem, J. Bouclé, F. Tran-Van, Carbazole-based molecular glasses for efficient solid-state dye-sensitized solar cells, J. Power Sources 233 (2013) 86-92.

[78] T.-T. Bui, S.K. Shah, M. Abbas, X. Sallenave, G. Sini, L. Hirsch, F. Goubard, Carbazole-based molecular glasses as hole-transporting materials in solid state dye-sensitized solar cells, ChemNanoMat 1 (2015) 203-210.

[79] F. Goubard, R. Aîcha, F. Tran-Van, A. Michaleviciute, F. Wünsch, M. Kunst, J. Grazulevicius, B. Ratier, C. Chevrot, Investigation of solid hybrid solar cells based on molecular glasses, Proc. Estonian Acad. Sci. Eng. 12 (2006) 96-110.

[80] T.-T. Bui, L. Beouch, X. Sallenave, F. Goubard, Carbazol- $N$-yl and diphenylamino end-capped triphenylamine-based molecular glasses: synthesis, thermal, and optical properties, Tetrahedron Lett. 54 (2013) 4277-4280.

[81] D. Liu, D. Li, H. Meng, Y. Wang, L. Wu, Multifunctional applications of triazine/ carbazole hybrid thermally activated delayed fluorescence emitters in organic light emitting diodes, J. Mater. Chem. C 7 (2019) 12470-12481.

[82] X.-D. Zhu, Q.-S. Tian, Q. Zheng, X.-C. Tao, Y. Yuan, Y.-J. Yu, Y. Li, Z.-Q. Jiang, L.-S. Liao, A sky-blue thermally activated delayed fluorescence emitter based on multimodified carbazole donor for efficient organic light-emitting diodes, Org. Electron. 68 (2019) 113-120.

[83] J.-L. Cai, W. Liu, K. Wang, J.-X. Chen, Y.-Z. Shi, M. Zhang, C.-J. Zheng, S.-L. Tao X.-H. Zhang, Highly efficient thermally activated delayed fluorescence emitter developed by replacing carbazole with 1,3,6,8-tetramethyl-carbazole, Front. Chem. 7 (2019) 17.

[84] T.-T. Bui, F. Goubard, M. Ibrahim-Ouali, D. Gigmes, F. Dumur, Thermally activated delayed fluorescence emitters for deep blue organic light emitting diodes: a review of recent advances, Appl. Sci. 8 (2018) 494

[85] T.-T. Bui, F. Goubard, M. Ibrahim-Ouali, D. Gigmes, F. Dumur, Recent advances on organic blue thermally activated delayed fluorescence (TADF) emitters for organic light-emitting diodes (OLEDs), Beilstein J. Org. Chem. 14 (2018) 282-308.

[86] K. Karon, M. Lapkowski, Carbazole electrochemistry: a short review, J. Solid State Electrochem. 19 (2015) 2601-2610.

[87] W. Li, M. Otsuka, T. Kato, Y. Wang, T. Mori, T. Michinobu, 3,6-Carbazole vs 2,7-carbazole: a comparative study of hole-transporting polymeric materials for inorganic-organic hybrid perovskite solar cells, Beilstein J. Org. Chem. 12 (2016) 1401-1409.

[88] G. Mohammadi, Z. Razieh, M. Negar, L.H.G. Kruger, Metal-Free Synthetic Organic Dyes, Elsevier Inc., Amsterdam, 2018, pp. 109-116 chap. 6.

[89] B.M. Gutsulyak, A.V. Turov, R.S. Petrovskii, M.Y. Kornilov, Synthesis of 3-methylpyrido[3,2,1-j, k] carbazolium salts and derived cyanine dyes, Chem. Heterocycl. Com. 23 (1987) 846-849.

[90] S. Aharonovich, N. Gjineci, D.R. Dekel, C.E. Diesendruck, An effective synthesis of N, N-diphenyl carbazolium salts, Synlett 29 (2018) 1314-1318.

[91] Y. Okada, H. Huruya, Y. Imori, Ligand exchange reaction of ferrocene with heterocycles, Int. J. Org. Chem. 5 (2015) 282-290.

[92] P. Xiao, J. Lalevée, J. Zhao, M.H. Stenzel, $N$-Vinylcarbazole as versatile photoinaddimer of photopolymerization under household UV LED bulb (392 nm), Macromol. Rapid Commun. 36 (2015) 1675-1680.

[93] J. Lalevée, M.-A. Tehfe, F. Morlet-Savary, B. Graff, X. Allonas, J.-P. Fouassier, Radical photopolymerization reactions under air upon lamp and diode laser exposure: the input of the organosilane radical chemistry, Prog. Org. Coat. 70 (2011) $83-90$.

[94] H. Mokbel, D. Anderson, R. Plenderleith, C. Dietlin, F. Morlet-Savary, F. Dumur D. Gigmes, J.-P. Fouassier, J. Lalevée, Copper PhotoRedox Catalyst "G1": a new 
high performance photoinitiator for near-UV and visible LEDs, Polym. Chem. 8 (2017) 5580-5592.

[95] H. Mokbel, D. Anderson, R. Plenderleith, C. Dietlin, F. Morlet-Savary, F. Dumur, D. Gigmes, J.-P. Fouassier, J. Lalevée, Simultaneous initiation of radical and cationic polymerization reactions using the "G1" copper complex as photoRedox catalyst: applications of free radical/cationic hybrid photo-polymerization in the composites and 3D printing fields, Prog. Org. Coat. 132 (2019) 50-61.

[96] J. Ortyl, M. Galica, R. Popielarz, D. Bogdał, Application of a carbazole derivative as a spectroscopic fluorescent probe for real time monitoring of cationic photopolymerization, Polish J. Chem. Technol. 16 (2014) 75-80.

[97] E. Knoevenagel, Über eine Darstellungsweise des Benzylidenacetessigesters, Ber. Dtsch. Chem. Ges. 29 (1896) 172-174.

[98] M.A. Amado-Briseño, L.A. Zárate-Hernández, K. Alemán-Ayala, O. Coreño Alonso, J. Cruz-Borbolla, J.M. Vásquez-Pérez, V. Esteban Reyes-Cruz, M.A. Veloz-Rodríguez, E. Rueda-Soriano, T. Pandiyan, R.A. Vázquez-García, Mechanosynthesis of photochromic oligophenyleneimines: optical, electrochemical and theoretical studies, Molecules 24 (2019) 849.

[99] M.-A. Tehfe, F. Dumur, B. Graff, F. Morlet-Savary, D. Gigmes, J.-P. Fouassier, J. Lalevée, Push-pull (thio)barbituric acid derivatives in dye photosensitized radical and cationic polymerization reactions under $457 / 473 \mathrm{~nm}$ Laser beams or blue LEDs, Polym. Chem. 4 (2013) 3866-3875.

[100] N.G. Bakshiev, Universal intermolecular interactions and their effect on the position of the electronic spectra of molecules in two component solutions, Opt. Spektrosk. 16 (1964) 821-832.

[101] E. Lippert, Dipolmoment und elektronenstruktur von angeregten molekülen, Z. Naturforsch. A: Phys. Sci. 10 (1955) 541-545.

[102] A. Kawski, Zur Iösungsmittelabhängigkeit der Wellenzahl von Elecktronenbanden lumineszierender Moleküle and über die Bestimmung der elektrischen Dipolomente im Anregungszustand, Acta Phys. Pol. 29 (1966) 507-518.

[103] E.G. McRae, Theory of solvent effects on molecular electronic spectra. Frequency shifts, J. Phys. Chem. 61 (1957) 562-572.

[104] P. Suppan, Solvent effects on the energy of electronic transitions: experimental observations and applications to structural problems of excited molecules, J. Chem. Soc. A 3125-3133 (1968).

[105] K.-T. Chen, D.-C. Cheng, J.-T. Lin, H.-W. Liu, Thiol-ene photopolymerization: scaling law and analytical formulas for conversion based on kinetic rate and thiol-ene molar ratio, Polymers 11 (2019) 1640.

[106] N.B. Cramer, J.P. Scott, C.N. Bowman, Photopolymerizations of thiol-ene polymers without photoinitiators, Macromolecules 35 (2002) 5361-5365.

[107] K.L. Wiley, E.M. Ovadia, C.J. Calo, R.E. Huber, A.M. Kloxin, Rate-based approach for controlling the mechanical properties of 'thiol-ene' hydrogels formed with visible light, Polym. Chem. 10 (2019) 4428-4440.

[108] J.D. McCall, K.S. Anseth, Thiol-ene photopolymerizations provide a facile method to encapsulate proteins and maintain their bioactivity, Biomacromolecules 13 (2012) 2410-2417.

[109] A. Al Mousawi, F. Dumur, P. Garra, J. Toufaily, T. Hamieh, B. Graff, D. Gigmes, J.-P. Fouassier, J. Lalevée, Carbazole scaffold based photoinitiators/photoredox catalysts for new LED projector 3D printing resins, Macromolecules 50 (2017) 2747-2758.

[110] J.-P. Fouassier, J. Lalevée, Photoinitiators for Polymer Synthesis, Scope, Reactivity, and Efficiency, Wiley-VCH Verlag GmbH \& Co.KGaA, Weinheim, 2012.

[111] J.-P. Fouassier, Photoinitiator, Photopolymerization and Photocuring: Fundamentals and Applications, Gardner Publications, New York, 1995.

[112] A. Al Mousawi, P. Garra, F. Dumur, T.-T. Bui, F. Goubard, J. Toufaily, T. Hamieh B. Graff, D. Gigmes, J.-P. Fouassier, J. Lalevée, Novel carbazole skeleton-based photoinitiators for LED polymerization and LED projector 3D printing, Molecules 22 (2017) 2143.

[113] J.-P. Fouassier, J. Lalevée, Polymers 6 (2014) 2588-2610.

[114] A. Al Mousawi, A. Arar, M. Ibrahim-Ouali, S. Duval, F. Dumur, P. Garra, J. Toufaily, T. Hamieh, B. Graff, D. Gigmes, J.-P. Fouassier, J. Lalevée, Carbazole-based compounds as photoinitiators for free radical and cationic polymerization upon near visible light illumination, Photochem. Photobiol. Sci. 17 (2018) 578-585.

[115] M. Abdallah, D. Magaldi, A. Hijazi, B. Graff, F. Dumur, J.-P. Fouassier, T.-T. Bui, F. Goubard, J. Lalevée, Development of new high performance visible light photoinitiators based on carbazole scaffold and their applications in 3D printing and photocomposite synthesis, J. Polym. Sci. A Polym. Chem. 57 (2019) 2081-2092.

[116] A. Sakalyte, R. Lazauskaite, J. Simokaitiene, G. Buika, J.V. Grazulevicius, 9-Ethyl-9H-carbazole in cationic photopolymerization, Des. Monomers Polym. 12 (2009) 331-342.

[117] G. Yilmaz, A. Tuzun, Y. Yagci, Thioxanthone-carbazole as a visible light photoinitiator for free radical polymerization, J. Polym. Sci. A Polym. Chem. 48 (2010) $5120-5125$.

[118] D.G. Anderson, R.S. Davidson, J.J. Elvery, Thioxanthones: their fate when used as photoinitiators, Polymer 37 (1996) 2477-2484.

[119] J.-P. Fouassier, D.J. Lougnot, Thioxanthone derivatives as photoinitiators in micelle photopolymerization, J. Appl. Polym. Sci. 34 (1987) 477-488.

[120] J.-P. Fouassier, S.K. Wu, Visible laser lights in photoinduced polymerization. VI. Thioxanthones and ketocoumarins as photoinitiators, J. Appl. Polym. Sci. 44 (1992) 1779-1786

[121] D.J. Lougnot, C. Turck, J.-P. Fouassier, Water-soluble polymerization initiators based on the thioxanthone structure: a spectroscopic and laser photolysis study, Macromolecules 22 (1989) 108-116.

[122] E. Andrzejewska, Photopolymerization kinetics of multifunctional monomers, Prog. Polym. Sci. 26 (2001) 605-665.
[123] M.A. Tasdelen, N. Moszner, Y. Yagci, The use of poly(ethylene oxide) as hydrogen donor in type II photoinitiated free radical polymerization, Polym. Bull. 63 (2009) 173-183.

[124] E. Andrzejewska, The influence of aliphatic sulfides on the photoinduced polymerization of butanediol-1,4 dimethacrylate, J. Polym. Sci. A Polym. Chem. 30 (1992) 485-491.

[125] M.A. Tasdelen, A.L. Demirel, Y. Yagci, Poly(propylene imine) dendrimer as hydrogen donor in type ii photoinitiated free radical polymerization, Eur. Polym. Mater. 43 (2007) 4423-4430.

[126] G. Bradley, R.S. Davidson, Some aspects of the role of amines in the photoinitiated polymerisation of acrylates in the presence and absence of oxygen, Recl. Trav. Chim. Pays-Bas 114 (1995) 528-533.

[127] L. Cokbaglan, N. Arsu, Y. Yagci, S. Jockusch, N.J. Turro, 2-Mercaptothioxanthone as a novel photoinitiator for free radical polymerization, Macromolecules 36 (2003) 2649-2653

[128] S. Keskin, S. Jockusch, N.J. Turro, N. Arsu, 2-Mercaptothioxanthone as sensitize and coinitiator for acylphosphine oxide photoinitiators for free radical polymerization, Macromolecules 41 (2008) 4631-4634.

[129] F. Karasu, N. Arsu, Y. Yagci, 2-Mercapto thioxanthone as a chain transfer agent in free-radical polymerization: a versatile route to incorporate thioxanthone moieties into polymer chain-ends, J. Appl. Polym. Sci. 103 (2007) 3766-3770.

[130] M. Aydin, N. Arsu, Y. Yagci, S. Jockusch, N.J. Turro, Mechanistic study of photoinitiated free radical polymerization using thioxanthone thioacetic acid as one-component type ii photoinitiator, Macromolecules 38 (2005) 4133-4138.

[131] M. Aydin, N. Arsu, Y. Yagci, One-component bimolecular photoinitiating systems, Macromol. Rapid Commun. 24 (2003) 718-723.

[132] F. Karasu, N. Arsu, S. Jockusch, N.J. Turro, Mechanistic studies of photoinitiated free radical polymerization using a bifunctional thioxanthone acetic acid derivative as photoinitiator, Macromolecules 42 (2009) 7318-7323.

[133] Q. Zhang, T. Komino, S. Huang, S. Matsunami, K. Goushi, C. Adachi, Triplet exciton confinement in green organic light-emitting diodes containing luminescent charge-transfer cu(i) complexes, Adv. Funct. Mater. 22 (2012) 2327-2336.

[134] H. Uoyama, K. Goushi, K. Shizu, H. Nomura, C. Adachi, Highly efficient organic light-emitting diodes from delayed fluorescence, Nature 492 (2012) 234-238.

[135] A. Al Mousawi, D. Magaldi Lara, G. Noirbent, F. Dumur, J. Toufaily, T. Hamieh, T.-T. Bui, F. Goubard, B. Graff, D. Gigmes, J.-P. Fouassier, J. Lalevée, Carbazole derivatives with thermally activated delayed fluorescence property as photoinitiators/photoredox catalysts for LED 3D printing technology, Macromolecules 50 (2017) 4913-4926.

[136] M. Bouzrati-Zerelli, N. Guillaume, F. Goubard, T.-T. Bui, S. Villotte, C. Dietlin, F. Morlet-Savary, D. Gigmes, J.-P. Fouassier, F. Dumur, J. Lalevée, A novel class of photoinitiators for polymerization reactions: organometallic and organic photoredox catalysts with a thermally activated delayed fluorescence (TADF) property, New J. Chem. 42 (2018) 8261-8270.

[137] Q. Zhang, J. Li, K. Shizu, S. Huang, S. Hirata, H. Miyazaki, C. Adachi, Design of efficient thermally activated delayed fluorescence materials for pure blue organic light emitting diodes, J. Am. Chem. Soc. 134 (2012) 14706-14709.

[138] P. Kaur, K. Singh, Recent advances in the application of BODIPY in bioimaging and chemosensing, J. Mater. Chem. C 7 (2019) 1136-11405.

[139] H.T. Bui, D.K. Mai, B. Kim, K.-H. Choi, B.-J. Park, H.-J. Kim, S. Cho, Effect of sub stituents on the photophysical properties and bioimaging application of bodipy derivatives with triphenylamine substituents, J. Phys. Chem. B 123 (2019) 5601-5607.

[140] Z. Liu, Z. Jiang, M. Yan, X. Wang, Recent progress of bodipy dyes with aggregation-induced emission, Front. Chem. 7 (2019) 712.

[141] A.M. Courtis, S.A. Santos, J. Guan, J.A. Hendricks, B. Ghosh, D. Miklos Szantai-Kis, S.A. Reis, J.V. Shah, R. Mazitschek, Monoalkoxy BODIPYs - A fluorophore class for bioimaging, Bioconjugate Chem. 25 (2014) 1043-1051.

[142] B. Jedrzejewska, B. Osmiałowski, Difluoroboranyl derivatives as efficient panchromatic photoinitiators in radical polymerization reactions, Polym. Bull. 75 (2018) 3267-3281.

[143] S. Telitel, N. Blanchard, S. Schweizer, F. Morlet-Savary, B. Graff, J.-P. Fouassier, J. Lalevée, BODIPY derivatives and boranil as new photoinitiating systems of cationic polymerization exhibiting a tunable absorption in the $400-600 \mathrm{~nm} \mathrm{spec}$ tral range, Polymer 54 (2013) 2071-2076.

[144] O. Garcia, A. Costela, I. Garcia-Moreno, R. Sastre, Pyrromethene 567 dye as visible light photoinitiator for free radical polymerization, Macromol. Chem. Phys 204 (2003) 2233-2239.

[145] C. Schmitz, A. Halbhuber, D. Keil, B. Strehmel, NIR-sensitized photoinitiated radical polymerization and proton generation with cyanines and LED arrays, Prog. Org. Coat. 100 (2016) 32-46.

[146] T. Brömme, C. Schmitz, N. Moszner, P. Burtscher, N. Strehmel, B. Strehmel, Photochemical oxidation of NIR photosensitizers in the presence of radical initiators and their prospective use in dental applications, ChemistrySelect 1 (2016) 524-532.

[147] C. Schmitz, B. Strehmel, NIR LEDs and NIR lasers as feasible alternatives to replace oven processes for treatment of thermal-responsive coatings, J. Coat. Technol. Res. 16 (2019) 1527-1541.

[148] A. Shiraishi, H. Kimura, D. Oprych, C. Schmitz, B. Strehmel, Comparison between NIR and UV-sensitized radical and cationic reactivity of iodonium salts comprising anions with different coordination behavior, J. Photopolym. Sci. Technol. 30 (2017) 633-638.

[149] B. Strehmel, C. Schmitz, T. Brömme, A. Halbhuber, D. Oprych, J. Gutmann, Advances of near infrared sensitized radical and cationic photopolymerization: from 
graphic industry to traditional coatings, J. Photopolym. Sci. Technol. 29 (2016) 111-121.

[150] J. Fabian, H. Nakazumi, M. Matsuoka, Near-infrared absorbing dyes, Chem. Rev. 92 (1992) 1197-1226.

[151] A. Al Mousawi, F. Dumur, P. Garra, J. Toufaily, T. Hamieh, F. Goubard, T.-T. Bui, B. Graff, D. Gigmes, J.-P. Fouassier, J. Lalevee, Azahelicenes as visible light photoinitiators for cationic and radical polymerization: preparation of photo-luminescent polymers and use in high performance LED projector 3D printing resins, J. Polym. Sci. A Polym. Chem. 55 (2017) 1189-1199.

[152] K. Meier, H. Zweifel, Imaging with iron arene photoinitiators, J. Image Sci. 30 (1986) 174-177.

[153] F. Lohse, H. Zweifel, Photocrosslinking of epoxy resins, Adv. Polym. Sci. 78 (1986) 62-69.

[154] T. Wang, Y.L. Huang, S.J. Shi, Studies on the photo-sensitivity of cationic polymerization photoinitiator [Cp-Fe-arene] $\mathrm{BF}_{4}$, Chem. J. Chin. Univ. 24 (2003) 735-739.

[155] T. Wang, L.J. Ma, P.Y. Wan, A study of the photoactivities and thermomechanical properties of epoxy resins using novel [cyclopentadien-Fe-arene] ${ }^{+} \mathrm{PF}_{6}{ }^{-}$photoinitiators, J. Photochem. Photobiol. A: Chem. 163 (2004) 77-86.

[156] A.N. Nesmeyanov, N.A. Vol'kenau, I.N. Boleaova, The interaction of ferrocene and its derivatives with aromatic compounds, Tetrahedron Lett. 25 (1963) 1725-1729.

[157] J.F. Helling, W.A. Hendrickson, $\pi$-cyclohexadienyliron complexes bearing exocyclic double bonds, J. Organomet. Chem. 141 (1977) 99-105.

[158] Y. Shi, G. Li, B. Zhao, Y. Chen, P. Chao, H. Zhang, X. Wang, T. Wang, Synthesis and optical properties of cationic cyclopentadienyl iron complexes with diphenylacetylene chromophores, Inorg. Chim. Acta 427 (2015) 259-265.

[159] I.U. Khand, P.L. Pauson, W.E. Watts, Dienyl complexes of transition metals. Part II. The addition of hydride to halogen-substituted arenecyclopentadienyliron cations, J. Chem. Soc. C: Org. (1968) 2261-2265.

[160] T. Karatsu, Y. Shibuki, N. Miyagawa, S. Takahara, A. Kitamura, T. Yamaoka, Mechanistic investigations of the photosensitized reactions of iron arene complexes, J. Photochem. Photobiol. A Chem. 107 (1997) 83-91.

[161] V. Andruleviciute, R. Lazauskaite, J.V. Gražulevicius, A. Stanišauskait, Cationic photopolymerization of carbazolyl- and phenothiazinyl-containing thiiranes, J. Photochem. Photobiol. A Chem. 147 (2002) 63-69.

[162] J.-P. Fouassier, D. Burr, J.V. Crivello, Photochemistry and photopolymerization activity of diaryliodonium salts, J. Macromol. Sci. 31 (1994) 677-701.

[163] R.S. Davidson, J.W. Goodwin, The polymerization of acrylates using a combination of a carbonyl compound and an amine as a photo-initiator system, Eur. Polym. J. 18 (1982) 597-606.

[164] E.J. Goethals, D. Van Meirvenne, R. De Clercq, Cationic degradation of polysulfides and polyethers by chemical initiators and irradiation, Macromol. Chem. Symp. 13 (1988) 175-191.

[165] T. Wang, J.W. Chen, Z.Q. Li, P.Y. Wan, Several ferrocenium salts as efficient photoinitiators and thermal initiators for cationic epoxy polymerization, J. Photochem. Photobiol. A Chem. 187 (2007) 389-394.

[166] A. Roloff, K. Meier, M. Riediker, Synthetic and metal organic photochemistry in industry, Pure Appl. Chem. 58 (1986) 1267-1272.

[167] J. Zhang, D. Campolo, F. Dumur, P. Xiao, D. Gigmes, J.-P. Fouassier, J. Lalevée, The carbazole-bound ferrocenium salt as a specific cationic photoinitiator upon near-UV and visible LEDs (365-405 nm), Polym. Bull. 73 (2016) 493-507.

[168] M. Kara, S. Dadashi-Silab, Y. Yagci, Phenacyl ethyl carbazolium as a long wavelength photoinitiator for free radical polymerization, Macromol. Rapid Commun. 36 (2015) 2070-2075.

[169] Y. Yagci, Y.Y. Durmaz, B. Aydogan, Phenacyl onium salt photoinitiators: synthesis, photolysis, and applications, Chem. Rec. 7 (2007) 78-90.

[170] E. Takahashi, F. Sanda, T. Endo, Photocationic and radical polymerizations by novel N-phenacylammonium salts, J. Appl. Polym. Sci. 91 (2004) 3470-3476.

[171] A. Nese, S. Sen, M.A. Tasdelen, N. Nugay, Y. Yagci, Clay-PMMA nanocomposites by photoinitiated radical polymerization using intercalated phenacyl pyridinium salt initiators, Macromol. Chem. Phys. 207 (2006) 820-826.
[172] M.A. Tasdelen, B. Karagoz, N. Bicak, Y. Yagci, Phenacylpyridinium oxalate as a novel water-soluble photoinitiator for free radical polymerization, Polym. Bull. 59 (2008) 759-766.

[173] N. Yonet, N. Bicak, Y. Yagci, Photoinitiated cationic polymerization of cyclohexene oxide by using phenacyl benzoylpyridinium salts, Macromolecules 39 (2006) 2736-2738.

[174] N. Yonet, N. Bicak, M. Yurtsever, Y. Yagci, Spectroscopic and theoretical investigation of capillary-induced keto-enol tautomerism of phenacyl benzoylpyridinium-type photoinitiators, Polym. Int. 56 (2007) 525-531.

[175] F. Kasapoglu, M. Aydin, N. Arsu, Y. Yagci, Photoinitiated polymerization of methyl methacrylate by phenacyl type salts, J. Photochem. Photobiol. A 159 (2003) 151-159.

[176] F. Kasapoglu, A. Onen, N. Bicak, Y. Yagci, Photoinitiated cationic polymerization using a novel phenacyl anilinium salt, Polymer 43 (2002) 2575-2579.

[177] Y.Y. Durmaz, Ö. Zaim, Y. Yagci, Diethoxy-azobis(pyridinium) salt as photoinitiator for cationic polymerization: towards wavelength tunability by cis-trans isomerization, Macromol. Rapid Commun. 29 (2008) 892-896.

[178] J. Kreutzer, K.D. Demir, Y. Yagci, Synthesis and characterization of a double photochromic initiator for cationic polymerization, Eur. Polym. J. 47 (2011) 792-799.

[179] E. Sari, G. Yilmaz, S. Koyuncu, Y. Yagci, Photoinduced step-growth polymerization of N-ethylcarbazole, J. Am. Chem. Soc. 140 (2018) 12728-12731.

[180] G. Yilmaz, Y. Yagci, Light-induced step-growth polymerization, Prog. Polym. Sci. 100 (2020) 101178

[181] E. Contal, C. Moussa Sougueh, S. Lakard, A. Et Taouil, C. Magnenet, B. Lakard, Investigation of polycarbazoles thin films prepared by electrochemical oxidation of synthesized carbazole derivatives, Front. Mater. 6 (2019) 131.

[182] B.H. Lessard, L. Beouch, F. Goubard, G. Wantz, M. Marić, D. Gigmes, F. Dumur, Poly(2-(N-carbazolyl)ethyl acrylate) as a host for high efficiency polymer light-emitting devices, Org. Electron. 17 (2015) 377-385.

[183] A. Danel, Ł. Chacaga, T. Uchacz, M. Pokladko-Kowar, E. Gondek, P. Karasinski, B. Sahraoui, Solution processable double layer organiclight emitting diodes (OLEDs) based on 6-N, N-arylsubstituted-1H-pyrazolo[3,4-b]quinolines, Adv. Device Mater. 1 (2015) 17-22.

[184] S. Lee, H. Koo, S. Cho, Mask-less patterning of organic light emitting diodes using electrospray and selective biasing on pixel electrodes, Appl. Phys. Lett. 106 (2015) 173303.

[185] Q. Chen, D.-P. Liu, M. Luo, L.-J. Feng, Y.-C. Zhao, B.-H. Han, Nitrogen-containing microporous conjugated polymers via carbazole-based oxidative coupling polymerization: preparation, porosity, and gas uptake, Small 10 (2014) 308-315.

[186] D.W. Wang, F. Li, J.-P. Zhao, W.C. Ren, Z.G. Chen, J. Tan, Z.S. Wu, I. Gentle, G.Q. Lu, H.M. Cheng, Fabrication of graphene/polyaniline composite paper viain situ anodic electropolymerization for high-performance flexible electrode, ACS Nano 3 (2009) 1745-1752.

[187] A.J.C. Kuehne, M.C. Gather, J. Sprakel, Monodisperse conjugated polymer particles by Suzuki-Miyaura dispersion polymerization, Nat. Commun. 3 (2012) 1088

[188] J. Schmidt, M. Werner, A. Thomas, Conjugated microporous polymer networks via yamamoto polymerization, Macromolecules 42 (2009) 4426-4429.

[189] B. Aydogan, A. Senol Gundogan, T. Ozturk, Y. Yagci, Polythiophene derivatives by step-growth polymerization via photoinduced electron transfer reactions, Chem. Commun. 41 (2009) 6300-6302.

[190] S. Dadashi-Silab, S. Doran, Y. Yagci, Photoinduced electron transfer reactions for macromolecular syntheses, Chem. Rev. 116 (2016) 10212-10275.

[191] B. Aydogan, Y. Yagci, L. Toppare, S. Jockusch, N.J. Turro, Photoinduced electron transfer reactions of highly conjugated thiophenes for initiation of cationic polymerization and conjugated polymer formation, Macromolecules 45 (2012) 7829-7834. 